\title{
LA IMPLANTACIÓN DE LAS GOTAS DE LECHE EN ESPAÑA (1902-1935): UN ESTUDIO A PARTIR DE LA PRENSA HISTÓRICA
}

\author{
Francisco Muñoz Pradas \\ Profesor Titular de la Universitat Autònoma de Barcelona \\ e-mail: francesc.munoz@uab.cat
}

Recibido: 25 mayo 2015; Aceptado: 5 febrero 2016.

Cómo citar este artículo/Citation: Muñoz Pradas, Francisco (2016), "La implantación de las Gotas de Leche en España (1902-1935): un estudio a partir de la prensa histórica", Asclepio 68 (1): p131. doi: http://dx.doi.org/10.3989/asclepio.2016.10

RESUMEN: Las Gotas de Leche eran instituciones sanitarias que intervinieron en la reducción de la mortalidad infantil en España promoviendo la mejora en la higiene alimentaria de los recién nacidos. Este artículo reconstruye la trayectoria de su implantación hasta la Guerra Civil. Dada la limitada información estadística disponible, se ha empleado como base documental las hemerotecas históricas digitalizadas. El análisis de la misma y de otros estudios permite estimar que el despliegue de esta institución entre 1902 y 1935 involucró, al menos, a 79 localidades. Se establecieron mayoritariamente en capitales de provincia, en todas las regiones, incluido el protectorado español en Marruecos. Antes de 1936 tuvo lugar una secuencia completa de expansión y estabilización en la apertura de estos centros. La creación de Gotas de Leche parece que respondió más a la influencia de las instituciones médicas y benéficas existentes en una localidad que a los niveles de mortalidad infantil. El examen de las noticias de prensa muestra como la creación de una Gota de Leche no acostumbró a ser fruto de un proceso de decisión ágil ejecutado rápidamente. La gestión tampoco estuvo exenta de dificultades. Una parte relevante de las mismas eran de origen financiero o derivadas de una mayor demanda de sus servicios.

PALABRAS CLAVE: Gotas de Leche; Mortalidad Infantil; Prensa Histórica; Instituciones Sanitarias; España.

\section{THE ESTABLISHMENT OF MILK DEPOTS IN SPAIN (1902-1935): A STUDY FROM THE HISTORICAL PRESS}

ABSTRACT: Milk Depots were health care institutions involved in fighting against high levels of child mortality in Spain in the first third of 20th century. They promoted the improvement of food hygiene of the newborn. This article reconstructs the trajectory of its implementation until the Spanish Civil War. Given the limited number of statistical sources available, it has been used as documentary source digitized historical newspapers. Analysis of these documents and other published studies leads to the estimation that this institution was deployed in 79 cities between 1902 and 1935. Milk Depots were settled mostly in provincial capitals, in all regions, including the Spanish protectorate in Morocco. Before 1936, a complete sequence of expansion and stabilization took place in the opening of these centers. This opening seems to respond most to influence of existing medical and charitable institutions that infant mortality levels prevailing at that time. Examination of the news shows as setting up a Milk Depot was not the outcome of a simple decision process, implemented quickly. The management was not exempt from difficulties. They came mainly from the lack of financial support or they were consequence from greater demand for their services.

KEY WORDS: Milk Depot; Infant mortality; Historical Press; Health Institutions; Spain.

Copyright: (c) 2016 CSIC. Este es un artículo de acceso abierto distribuido bajo los términos de la licencia Creative Commons Attribution (CC BY) España 3.0. 


\section{INTRODUCCIÓN}

En las sociedades europeas más avanzadas de finales del Ochocientos existía una preocupación por los altos niveles de mortalidad infantil. Esta percepción se fundamentaba en las estimaciones publicadas regularmente por organismos estadísticos nacionales, o locales, desde la segunda mitad del siglo XIX (Dûpaquier, 1985, pp. 342-348). En este escenario debe situarse la formación de movimiento internacional, con una notable presencia en Europa, dirigido a la mejora del bienestar de la población infantil (Cunningham, 2005 , p. 155). Al amparo de tal movimiento no solo se elaboraron políticas públicas, por ejemplo, regulando la edad de acceso al trabajo y los horarios laborales sino que también se constituyeron asociaciones privadas o comunidades locales movilizadas para mejorar las condiciones de vida de dicho sector de la población (Porter, 1999, pp. 173-182). Este mismo contexto contribuyó a la denominada "medicalización de la infancia» con la puesta en práctica de intervenciones sanitarias encaminadas a mejorar el desarrollo infantil desde el nacimiento, a través de la supervisión del comportamiento de las madres (Cunningham, 2005, p.155). Desde una perspectiva institucional una de estas intervención es fue la creación de las Gotas de Leche. Su propósito principal era incrementar la sobrevivencia de los recién nacidos mediante la mejora de los hábitos alimentarios, particularmente entre las clases sociales urbanas más empobrecidas. Esta atención puesta en la higiene alimentaria infantil era uno de los rasgos distintivos de la mencionada medicalización de la población infantil (Apple, 1987, pp. 72-96).Las raíces de esta institución partían de las dificultades experimentadas desde el siglo XVIII por asilos u orfanatos en la alimentación de los niños abandonados. En concreto, la repetida constatación que el recurso a las nodrizas no los libraba de unos elevados riesgos de morir.

Suelen considerarse pioneras las Gotas de Leche establecidas en Francia a partir del último decenio del siglo XIX, bajo la iniciativa de médicos como Pierre Budin, Gaston Variot y Léon Dufour (Rollet, 1990, pp. 355-389). Estos centros se expandieron por Europa y llegaron también a América (del Norte y del Sur). La modalidad francesa de organización de las Gotas de Leche fue muy influyente, si bien no resultó la única. Los países anglosajones organizaron la asistencia inicialmente de forma algo distinta. Esta característica era fruto del diferente papel de las enfermeras en el seguimiento de madres y recién nacidos, si bien a lo largo del primer tercio del siglo XX tales prácticas tendieron a asemejarse entre los países (McCleary,
1904, pp. 329-337; Marland, 1992, p.79). Que tal movimiento tenía alcance internacional, lo atestiguaron los Congresos de las Gotas de Leche celebrados los años 1905 (Paris), 1907 (Bruselas) y 1911 (Berlín) con la participación, en el último, de representantes de 34 países de todos los continentes, si bien la mayor parte de ellos europeos (Rollet 2001).

La España contemporánea de aquellas naciones europeas participó de igual preocupación por los altos niveles de mortalidad infantil (Rodríguez Ocaña, 1996, pp. 149-153; Barona, 2007) y aunque con cierto retraso respecto las estadísticas de mortalidad europeas también empezó a producir, en los primeros año del siglo $\mathrm{XX}$, los datos y a publicar los estudios que certificaban el alcance de tal fenómeno (Rodríguez Ocaña, 1985b, p. 444). De igual modo desarrolló una legislación de protección de la infancia y desplegó desde inicios del siglo $X X$, principalmente bajo iniciativa privada, instituciones como las Gotas de Leche. Como sus homólogas europeas, fueron establecimientos urbanos en una etapa inicial para después, particularmente durante la Segunda República, promocionar su mayor difusión en las zonas rurales (Rodríguez Ocaña, 1985b, pp. 455-58). En definitiva, España no quedó tampoco al margen de ese movimiento internacional. Una prueba de ello fue la presencia continuada de representantes españoles en los tres encuentros internacionales mencionados ${ }^{1}$.

Ahora bien, aunque estamos ante una institución sanitaria relevante en la lucha contra la mortalidad infantil en España, no se dispone todavía de una visión de conjunto sobre su organización y evolución histórica. No ayuda a esta tarea el hecho que las Gotas de Leche tuvieron una existencia básicamente local y la Administración española no llegó a reunir, publicar y analizar regularmente información sobre su actividad. Dado este contexto, no puede extrañar que gran parte de la investigación se haya orientado hacia la elaboración de monografías locales ${ }^{2}$. Desde una perspectiva más general, la historiografía ha subrayado tres características de este fenómeno en España (Rodríguez Ocaña, et al., 1985a): a) El escaso número de localidades que las implantaron, si se comparan con las abiertas en Francia o Alemania. b) Su influencia en el desarrollo de un mercado para nuevos productos alimentarios para los niños. c) Su efecto positivo en la difusión de nuevas prácticas de higiene relacionadas con la alimentación de la lactancia materna y del niño en general.

Más allá de este primer balance y de los detalles de su vida institucional, revelados por aquellos estudios monográficos, debe reconocerse que falta por reconstruir un aspecto básico como es el relativo a la secuen- 
cia cronológica y territorial del despliegue de la institución. En otras palabras, el proceso mismo de implantación de las Gotas de Leche en España. El objetivo de este artículo es ofrecer una primera visión de conjunto de su difusión hasta antes de la Guerra Civil. Se acota así al período en el que tuvo lugar el mismo fenómeno en otras naciones europeas. Además, tras finalizar la guerra española, las Gotas de Leche pierden su estatus como consecuencia de la promulgación de la ley de Sanidad Infantil y Maternal en 1941 y de la creación del Seguro Obligatorio de Enfermedad de 1942 (De Arana y Zafra Anta, 2014, p.33). Este estudio se aborda en dos etapas, en la primera, mediante el recuento del número y distribución de estos centros a lo largo de la geografía española y, en la segunda, con el análisis de los aspectos relacionados con las modalidades de su establecimiento y localización. Esta más allá de la extensión reservada a un artículo tratar otros aspectos que serían igualmente relevantes para la historia de las Gotas de Leche. Aquí pueden mencionarse, por ejemplo, los relativos al funcionamiento y los recursos humanos utilizados o al impacto de su apertura sobre los niveles la mortalidad infantil de las respectivas localidades ${ }^{3}$. Este escrito se estructurará en tres apartados. El primero, destinado a la presentación de las fuentes y la metodología. El segundo, a la reconstrucción de las tendencias cronológicas y territoriales en la difusión de las Gotas de Leche. El tercero, dedicado a ilustrar, a través de algunos casos, aspectos relativos a los procesos de creación y organización de los centros. Una conclusión resumirá los resultados principales e intentará situarlos en el contexto de la salud pública de la España del primer tercio del siglo XX.

\section{DATOS Y METODOLOGÍA}

Suele considerarse como precedente las Gotas de Leche establecidas en España el consultorio abierto por el doctor Francisco Vidal Solares en el Hospital de Niños Pobres de Barcelona el año 1890. Sin embargo, se trataba de una consulta destinada más a seguir y asesorar a las madres sobre la alimentación infantil que a proveer de leche esterilizada a los recién nacidos con dificultades para acceder a la lactancia natural ${ }^{4}$. En este sentido, estaría más próxima al denominado "Consultorio de Niños de Pecho». Este tipo de centros también se establecieron en distintos lugares de la geografía española en las primeras décadas del siglo XX, como el año 1904 en Tortosa y Valencia, creados por los doctores Manuel Vila y Joaquín Aguilar respectivamente o en 1905 en Pamplona, por la Sociedad Católica del Trabajo (Ulecia, 1912).
Un establecimiento con las características propias de una Gota de Leche se inauguró en Barcelona el año 1903, impulsado por el Ayuntamiento y precedente de la Casa de Lactancia abierta en 1913 (Rodríguez Ocaña, 1999, p. 295; Ayuntamiento de Barcelona 1913, pp. 314-318). En 1903, bajo el auspicio de las Cajas de Ahorro Provincial y Municipal se creó una Gota de Leche en San Sebastián (Urkia Etxabe, 1999, p.162). El mismo año en Bilbao se fundó una para el uso exclusivo de los niños de la inclusa (Ulecia, 1912) (Gondra, 2003). En Madrid, en 1904, el Dr. Rafael Ulecia abría su consulta, con el patrocinio de los marqueses de Casa-Torre (Maján, 1990, p.351), y, el mismo año, lo hacía la Gota de Leche de la ciudad de Logroño (Cerrillo, Iruzubieta y Fandino, 2008, pp. 76-77). Estos serían los primeros pasos de esta institución en España. A partir de entonces y hasta 1912 se cifra en torno a una treintena el total de Gotas de Leche activas en el país (Rodríguez Ocaña et al., 1985, p. 1068). De hecho, tanto el número, o el listado nominal, de estos centros que han publicado los historiadores suele corresponder al elaborado por los médicos de la época, como el mencionado Dr. Rafael Ulecia. El mismo fue un activo difusor de las Gotas de Leche y representante oficial de España en los congresos internacionales sobre la materia como el mencionado celebrado en Berlín el año 1911. Allí presentó su informe "Consultation für Brustkinder und Gouttes de Lait» ofreciendo un elenco, tanto de los Consultorios de Niños de Pecho como de las Gotas de Leche existentes entonces en España (Ulecia, 1912). Pero, aparte de estas informaciones de carácter general, como ya se observó anteriormente, las características de la expansión cronológica y territorial de estos centros en España son todavía poco conocidas. No parece haber existido ningún registro sistemático de su número y evolución. Las dos únicas fuentes estadísticas disponibles para obtener una visión global de esta institución serían «Los Nuevos apuntes para el estudio y la organización de las instituciones de beneficencia y de la Previsión», publicados por el Ministerio de Gobernación (Ministerio Gobernación, 1912-1918, p. 480) y el «Anuario Estadístico de España» durante los años 1916 a $1923^{5}$. Al listado de las localidades y establecimientos reproducido allí habría que añadir el mencionado informe del Dr. Rafael Ulecia en la conferencia internacional de Berlín.

La primera fuente citada contiene un inventario de Gotas de Leche, junto a otras instituciones benéficas encargadas del cuidado de los niños durante la lactancia. Los datos probablemente fueron recogidos hasta principios de 1910 (el año más tardío mencionado con inauguraciones de centros) y, al menos, se habrían reunido desde 1906, cuando una circular del Inspector 
General de Sanidad Exterior, publicada en los Boletines Oficiales Provinciales, solicitaba este tipo de información ante la convocatoria del que sería el congreso internacional de Bruselas del año $1907^{6}$. La lista de Gotas de Leche comprendía un total de 26 centros repartidos en 22 localidades, si bien el número de estas últimas llegaría a las 31 si se contabilizan otras 9 en las que en la misma publicación se hace constar tan sólo la distribución de litros de leche. La segunda fuente, los anuarios estadísticos, ofrece información sobre niños atendidos y litros de leche consumidos en Gotas de Leche en capitales de provincia, publicadas regularmente entre 1916 y 1923 . Este listado incluye para todos estos años 37 localidades, en las que se encuentran todas las capitales mencionadas en "Los Nuevos apuntes...», con excepción de Zamora, que no consta en aquellos y si en los anuarios y León, en la situación opuesta. Como es lógico, dado que la cobertura cronológica de los anuarios es superior a la del otro documento, el número de nuevas localidades que se establecen a partir de 1918 incrementa la cifra hasta las 37 mencionadas.

La lista de establecimientos presentada por el doctor R.Ulecia en su intervención en el congreso de Berlín reúne 31 centros, contabilizando tanto los Consultorios de Niños de Pecho (6), como las Gotas de Leche (25 restantes). Estos se distribuyen en 23 localidades, entre las cuales, solamente dos, Santa Cruz de Tenerife o Tortosa no aparecen en ninguno de los recuentos anteriores ${ }^{7}$. Circunstancia esta explicable porque en el caso de la primera, la Gota de Leche, al parecer, sólo estuvo abierta unos pocos meses y, en el de la segunda, porque se trataba de un Consultorio de Niños de Pecho y, por tanto, no dispensaba los servicios propios del otro tipo de establecimiento.

Si nos atenemos al horizonte temporal de toda esta documentación hasta ahora citada, resulta obvio que no permite una reconstrucción cronológica que alcance hasta los prolegómenos de la Guerra Civil. A esta limitación siempre habría que sumar la derivada de las posibles faltas de exhaustividad o de exactitud en el recuento de Gotas de Leche en activo por esas fuentes. A la vista, pues, de estos inconvenientes la estrategia adoptada se ha dirigido a rastrear la información sobre estos centros publicada en la prensa diaria española del primer tercio del siglo XX. Esta tarea habría resultado ingente en otra época. Hoy en día, en cambio, la combinación, por una parte, de la digitalización de colecciones de la prensa histórica con, por la otra, la existencia de robots o sistemas de lectura automática, permite llevar a cabo un cribado sistemático de las noticias publicadas relativas a la existencia y actividad de estos centros. Es necesario, pues, detallar las fuentes consultadas y el procedimiento de búsqueda adoptado.
Con objeto de obtener información a escala provincial y regional se ha utilizado principalmente la «Biblioteca Virtual de la Prensa Histórica Española» (BVPH) ${ }^{8}$. Constatada en esta biblioteca la falta de prensa correspondiente a la Región de Murcia, se ha consultado el «Archivo Digital de Murcia» (ADM) ${ }^{9}$. Para acceder a la prensa con cobertura en todo el territorio español se han utilizado las Hemerotecas digitales de «La Vanguardia» y el diario «ABC». En todos los casos, pues, se trata principalmente de lo que se denominaría prensa diaria, si bien, entre los fondos digitalizados y accesibles a la lectura automática, también se han encontrado publicaciones periódicas como semanarios, revistas médicas o boletines oficiales de la provincia. Las mayoría de las consultas tuvieron lugar entre el 18/12/ 2011 y el 17/06/ 2012. Una última actualización, básicamente dirigida a comprobar las ampliaciones producidas en el elenco de publicaciones accesibles a los robots de lectura, se produjo entre el 20/06 y el 28/06 del 2014. En todos los casos la búsqueda de noticias se asoció al término "Gota de Leche», otros como «Consultorio de niños de pecho», "Casas de Lactancia» o "Auxilios de Leche» se descartaron una vez verificado que proporcionaban substancialmente un menor número de noticias. Además, estos términos denotaban, como se ha observado antes, formas de organizar la atención a la alimentación de los recién nacidos de naturaleza muy distinta de la propia de una Gota de Leche.

En la Tabla 1 se ofrece el inventario de la frecuencia de noticias y el número de cabeceras rastreadas, por períodos quinquenales, entre 1900 y 1934, obtenidos a partir de la BVPH y el ADM. La Tabla 2, repite el mismo tipo de información recopilada ahora a partir de las Hemerotecas históricas de "La Vanguardia» y el «ABC». En conjunto se han reunido 7.884 referencias capturadas de un total 216 cabeceras. En relación a esta documentación, cobertura geográfica y temporal y su tratamiento posterior es necesario hacer las siguientes observaciones:

a) No todas las cabeceras catalogadas en la BVPH tienen habilitado el procedimiento de búsqueda automática. La consecuencia más visible de esta observación se aprecia en la Tabla 1. Puede constatarse en ella que existen territorios prácticamente sin referencia alguna. Así, con menos de 20, se encontrarían la Región de Murcia, seguida de Asturias y, con menos de 100, Galicia y Navarra. Además, se aprecian también las discontinuidades cronológicas de las referencias, fruto combinado de la vida temporal de cada publicación con el número de cabeceras digitalizadas disponibles para la búsqueda automática. 
b) Dado que el carácter parcial o fragmentario de la base de datos de la prensa histórica utilizada podría suponer algún tipo de sesgo respecto la provisión de noticias, se decidió explorar sistemáticamente las hemerotecas de "La Vanguardia» y «ABC» (edición de Madrid y de Sevilla). Con esta búsqueda se ha intentado complementar la exploración en la BVPH en dos aspectos esenciales para el propósito de este trabajo, la cobertura cronológica y territorial. Este último resulta de particular interés porque así se garantiza la recepción de noticias del conjunto del territorio español, esto es, un alcance mayor que el de la prensa local, fuertemente representada en la base digital de la prensa histórica. Como se puede comprobar en las Figuras 1 y 2, la distribución de frecuencias absolutas de referencias de ambos bloques informativos es muy próxima, lo que invitaría a concluir el carácter complementario de ambas búsquedas. Como es lógico, esta complementariedad entre fuentes periodísticas permite, además, contrastar las noticias existentes para un mismo lugar y acontecimiento.

c) La base de referencias generada en las dos operaciones de búsqueda descritas vendría a ser el equivalente a una base «bruta». Debe tenerse en cuenta que, bajo la voz "Gota de Leche», los programas de lectura automática detectan tanto la mención al establecimiento sanitario como, por ejemplo, la publicidad de cualquier producto o servicio en la que aparece igual término. De este modo, una parte de la tarea de esta investigación ha consistido en depurar o filtrar entre todas las noticias seleccionadas, las relativas a las Gotas de Leche como institución propiamente dicha. La base documental de este trabajo consiste, pues, en la combinación de las escasas estadísticas contemporáneas y la explotación de las fuentes periodísticas como base para intentar una reconstrucción de la expansión de esta institución sanitaria en la España anterior a la Guerra Civil ${ }^{10}$.

Una estrategia metodológica de esta naturaleza presenta sus correspondientes limitaciones. En este punto conviene atender a las siguientes: a) La falta de cobertura sistemática de todas las cabeceras por el robot de búsqueda puede dar paso a sesgos territoriales o cronológicos en la información de la vida de estos centros. b) La existencia de vacíos documentales esporádicos en la continuidad cronológica de las colecciones de las cabeceras. El control exhaustivo de los mismos hubiera alargado substancialmente la tarea de recogida de datos. c) Noticias relacionadas de forma relevante con una Gota de Leche en particular pero en las que la redacción de la misma no incluyó este término y, por lo tanto, no han sido detectadas a través de la lectura automática ${ }^{11}$.

A todos estos factores anteriores habría que añadir dos más, que no por menos obvios deben ser olvidados. Uno es, el relativo a la calidad y exhaustividad de la información publicada. En algunos casos, las noticias no dejan claro la situación real de la Gota de Leche. Así, por ejemplo, cuando se mencionan actividades benéficas "pro Gota de Leche». La existencia de información previa sobre su inauguración permite una interpretación distinta a si esta circunstancia no se está confirmada; en este caso y sin datos adiciones, no parece que pueda ser empleada fiablemente como indicio de presencia de una Gota de Leche en una localidad determinada. El otro factor tendría que ver con el hecho que la actividad de este tipo de establecimiento, simplemente no hubiera llamado la atención para su reseña en una publicación periódica ${ }^{12}$.

Por último es necesario hacer algunas observaciones en relación a la naturaleza de las noticias periodísticas reunidas en este trabajo. Es importante remarcar que proporcionan tres niveles distintos de información. El primero, relativo a la apertura del establecimiento, con sus antecedentes y consecuencias, si es el caso. El segundo correspondería a una referencia de la existencia de la Gota de Leche, sin contar con más información sobre el momento de su implantación. El tercero comprendería todas aquellas otras noticias sobre la actividad de la institución. Esto último abarcaría desde la apertura de segundos o terceros establecimientos, al traslado hacia otros edificios, pasando por las obras de mejora, las renovaciones de material o cualquier otro acto de contenido relacionado con los anteriores. Este conjunto de informaciones publicadas permite aplicar dos aproximaciones al estudio de la implantación de las Gotas de Leche. Una, ajustada a la implantación o apertura del establecimiento y la correspondiente puesta en marcha de sus servicios y la otra, atendiendo al grado de dinamismo posterior. De este modo, mientras la primera ayudaría a reconstruir lo que vendría a ser estrictamente la difusión de la institución, la segunda captaría la intensidad de su actividad. Obviamente, todas las Gotas de Leche compartirían un acto inaugural, o asimilado, como inicio de sus tareas, en cambio, la intensidad de sus actividades posteriores variaría entre ellas. Como se comentará más adelante, sólo de forma excepcional alguna apertura de una Gota de Leche terminó con el cierre del establecimiento, al menos durante el período estudiado aquí. 


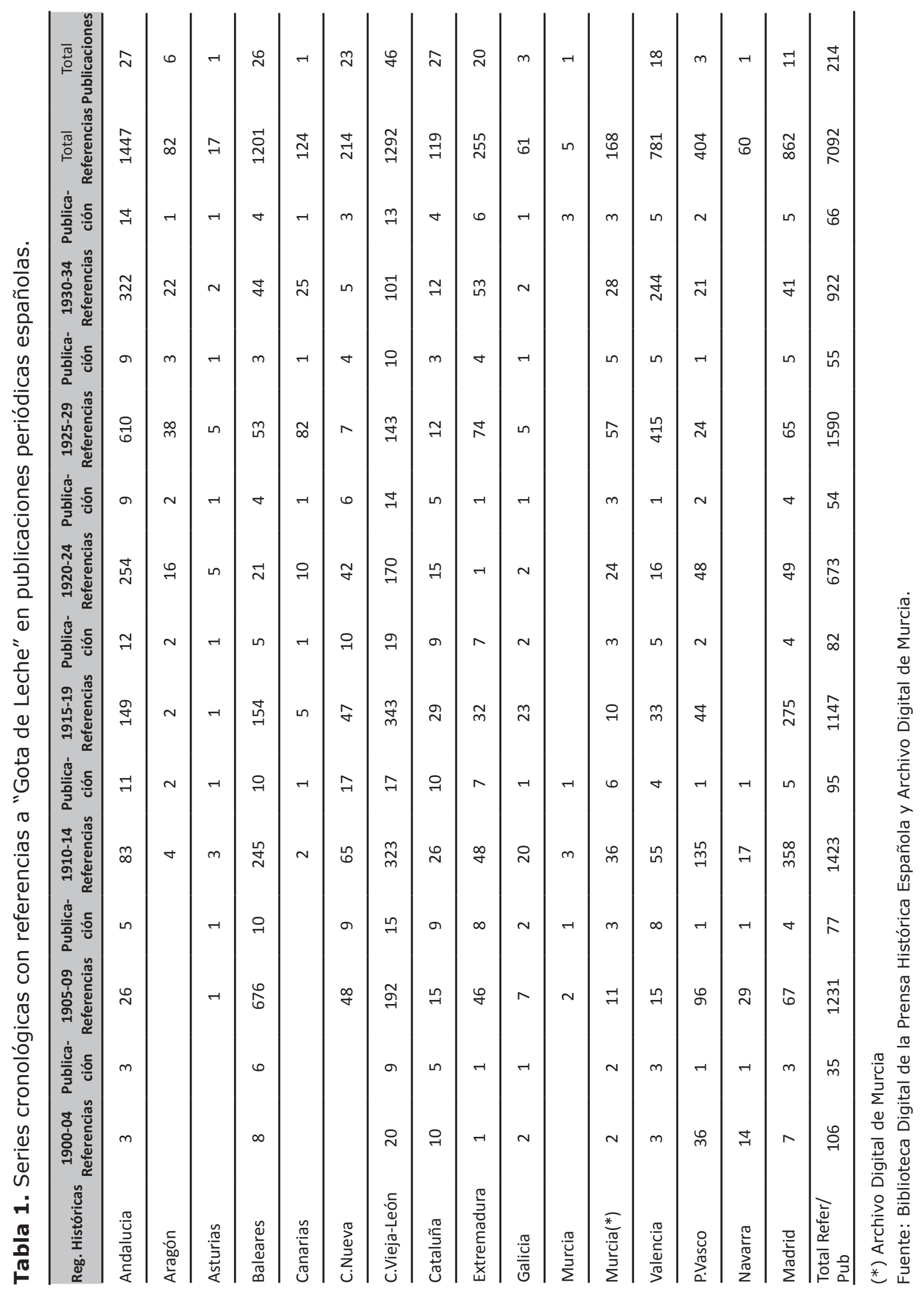


Tabla 2.Serie cronológica de referencia a "Gotas de Leche" publicadas en La Vanguardia y ABC

\begin{tabular}{lccccccc}
\hline Hemeroteca & $\mathbf{1 9 0 0 - 0 4}$ & $\mathbf{1 9 0 5 - 0 9}$ & $\mathbf{1 9 1 0 - 1 4}$ & $\mathbf{1 9 1 5 - 1 9}$ & $\mathbf{1 9 2 0 - 2 4}$ & $\mathbf{1 9 2 5 - 2 9}$ & $\mathbf{1 9 3 0 - 3 4}$ \\
\hline La Vanguardia & 2 & 34 & 96 & 92 & 56 & 108 & 55 \\
\hline ABC-Madrid & 4 & 49 & 67 & 56 & 50 & 69 & 54 \\
\hline Total & 6 & 83 & 163 & 148 & 106 & 177 & 109 \\
\hline
\end{tabular}

Fuente: Hemerotecas digitales de La Vanguardia y $A B C$.

Figura 1. Distribución de noticias sobre "Gota de Leche" en la prensa regional

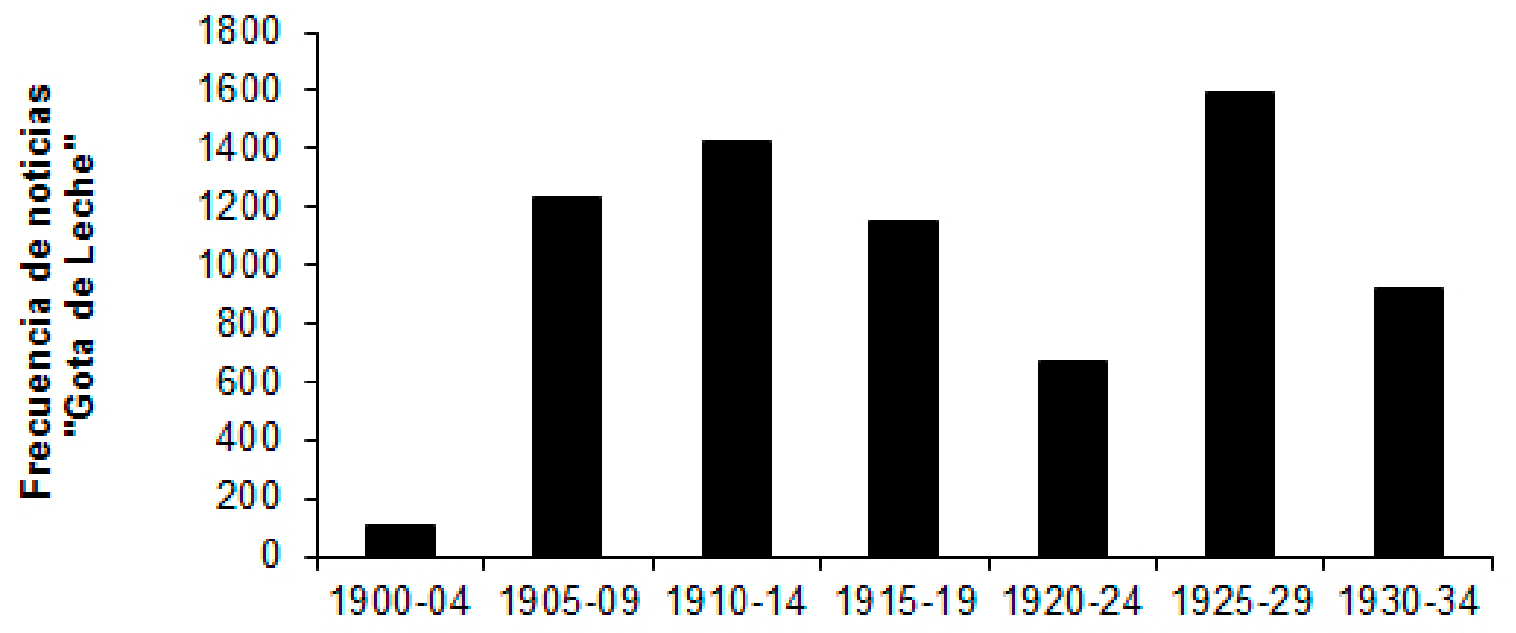

Fuente: Tabla 1

Figura 2. Distribución de noticias sobre "Gota de Leche" en La Vanguardia y $A B C$

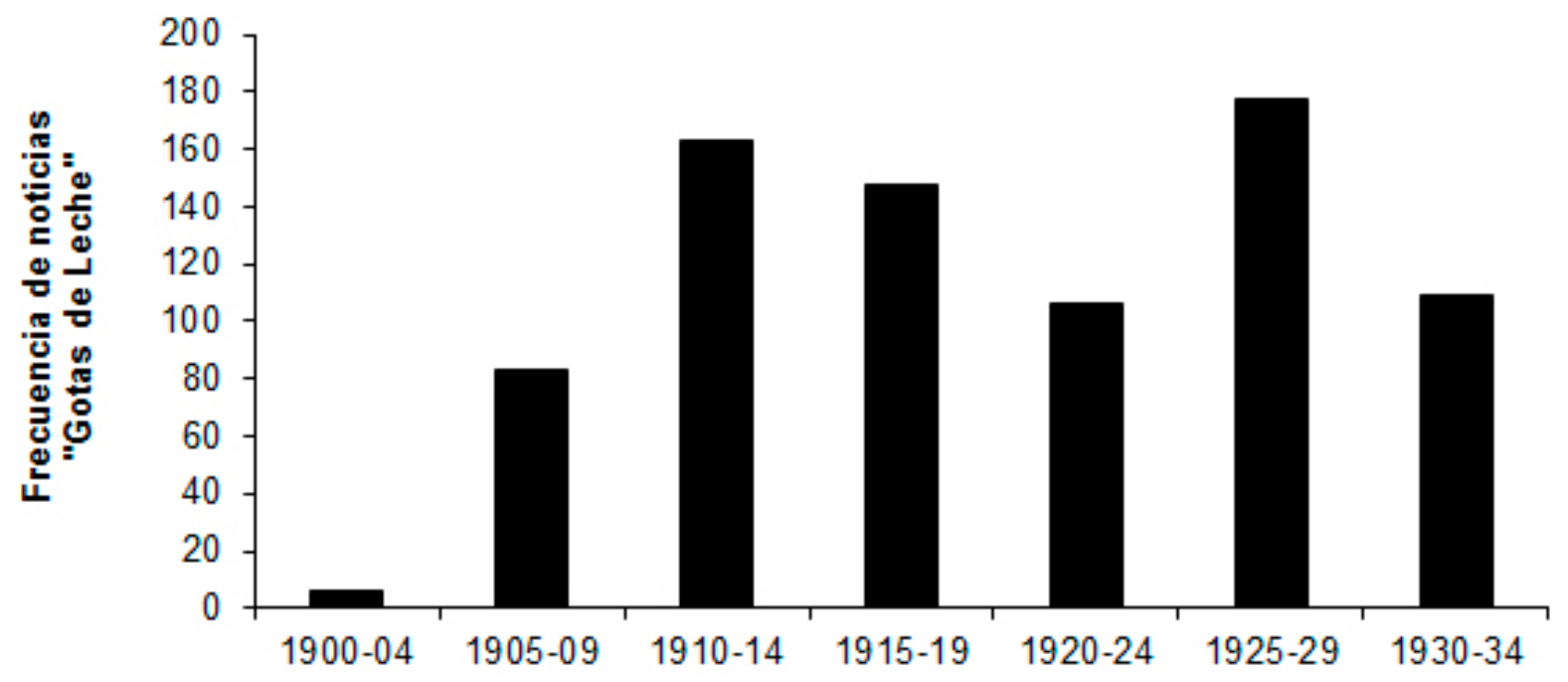

Fuente: Tabla 2 


\section{GOTAS DE LECHE EN ESPAÑA: LISTADO Y EXPANSIÓN CRONOLÓGICA Y TERRITORIAL}

A partir de las fuentes referidas en el apartado anterior se han confeccionado el listado de localidades con Gotas de Leche reunidos en los anexos 1 y 2 de este artículo. Es importante advertir que los listados se refieren a localidades y no a los establecimientos. Debe recordarse que en algunas ciudades se abrieron más de una Gota de Leche. De acuerdo a las informaciones publicadas en "Los Nuevos apuntes..." y las reunidas por algunos autores (Rodríguez Ocaña et al., 1985a, p.1068) en Barcelona, Madrid, en Bilbao, Jaén, Valencia, Sevilla y Zaragoza se llegaron a abrir hasta dos o tres de estos centros. Sin embargo, evidencia de esta multiplicación de establecimientos en el seno de una misma localidad no se ha observado claramente en las noticias recogidas a lo largo de esta investigación, con excepción de las ciudades de Madrid y Barcelona. Por tanto, en este trabajo será más el recuento del número de localidades que el de centros el que orienta la reconstrucción de la implantación de las Gotas de Leche en España hasta la Guerra Civil.

El anexo 1 reúne las localidades de las que se tiene noticia contrastada sobre el año de inauguración de un establecimiento o puede establecerse con cierta garantía. En este último caso se trata de lugares para los que consta, tanto información sobre preparativos previos como sobre actividad asistencial posterior a su inauguración, siempre que los años que medien entre ambas sean próximos. De este modo, este anexo comprende mayoritariamente primeras inauguraciones, aunque también se menciona información relativa a traslados o ampliaciones de edificios. El conjunto de referencias cubre 63 localidades. Se trata de un número inferior al compilado en el Anexo 2, con un listado en orden alfabético, de 86 ciudades. En él aparecen, además de las enumeradas en el Anexo 1, aquellas para las que se ha encontrado alguna noticia de actividad, aunque se desconozca la fecha de su inauguración. También se han incorporado las propuestas hechas en su momento para la implantación de estos centros en lugares en los que no se ha confirmado funcionamiento posterior. Además, se reproducen algunas informaciones relevantes para el seguimiento de la actividad de aquellas Gotas de Leche con fechas de inauguración conocidas. De no mediar, pues, otros datos no capturados en el proceso de lectura automática el Anexo 2 ofrecería el listado completo de localidades con Gotas de Leche en España anteriores a 1936 identificadas en el curso de esta investigación. En base a los mismos pueden establecerse las coordenadas espaciales y temporales de su implantación, que constituyen el propósito de las Tablas 3 y 4 y las Figuras 3,4 y 5.
La Figura 3 representa la distribución cronológica de las localidades con alguna Gota de Leche según las fechas de inauguración (Anexo 1). La secuencia que resulta permite apreciar con claridad la sucesión de una etapa de expansión y otra de reducción en la apertura de estos establecimientos. El quinquenio 1915-19 marcaría el periodo de tránsito entre una y otra. La Tabla 3 distingue entre las Gotas de Leche establecidas en capitales de provincia o en otras ciudades. A partir de la observación de la misma y de la figura mencionada se desprende que de aquellas dos grandes etapas, la primera, hasta 1920, concentraría más de la mitad de todas las inauguraciones con fecha conocida, con una notable presencia de las capitales de provincia (32 de 40). La segunda, claramente visible a partir de 1920 , se advierte no sólo una progresiva caída en el ritmo de apertura de nuevos establecimientos, sino, además, una relativa mayor presencia de localidades que no ostentaban aquella condición.

Los datos relativos a las capitales de provincia de la Tabla 3 se deben complementar con las referencias reunidas en el Anexo 2. De este modo se constata como, a las puertas del conflicto civil, la actividad de estos centros se habría extendido a casi la totalidad de las mismas. Las únicas para las que no ha sido posible constatar la presencia de Gotas de Leche han sido Ávila, Lugo y Pontevedra. Otra sería la situación de Soria, donde los intentos de crearla en 1915 («El Porvenir Castellano», 15 Enero 1915) parecen todavía continuar en 1930 («Noticiero de Soria», 17 Julio 1930); de Teruel, con una propuesta presentada en 1926 («El Diario de Teruel», 12 Agosto 1926) y de Gerona, aquí el proyecto data del año 1910 («Heraldo de Gerona», 1 de Diciembre 1910). En estos tres lugares, después de estas noticias reseñadas, no se ha encontrado confirmación posterior de la apertura de un establecimiento. En definitiva, en seis de las cincuenta capitales de provincia no se ha podido documentar una presencia activa de esta institución.

La cronología en la implantación de las Gotas de Leche esbozada más arriba, se matizaría a la vista de los datos reunidos en la Tabla 4 y la Figura 4. En esta última se representan el conjunto de localidades del Anexo 2, esto es, aquellas con año de inauguración conocido más las que se ha encontrado alguna noticia de su existencia, sin tener documentado el inicio de sus actividades, eliminando de ese listado a las localidades sin evidencia de Gotas de Leche en funcionamiento ${ }^{13}$. Si suponemos que la diferencia temporal entre esa noticia de su existencia y la apertura del establecimiento no supera 
Tabla 3. Frecuencia de Gotas de Leche inauguradas (Total y en capitales de provincia)

\begin{tabular}{lcc}
\hline Período & Total & en Capitales \\
\hline $1900-04$ & 5 & 5 \\
\hline $1905-09$ & 13 & 8 \\
\hline $1910-14$ & 11 & 9 \\
\hline $1915-19$ & 15 & 10 \\
\hline $1920-24$ & 6 & 3 \\
\hline $1925-29$ & 9 & 1 \\
\hline $1930-34$ & 4 & 40 \\
\hline Total & 63 & \\
\hline
\end{tabular}

Fuente: Anexo 1.

Figura 3. Cronología de localidades con Gotas de Leche inauguradas
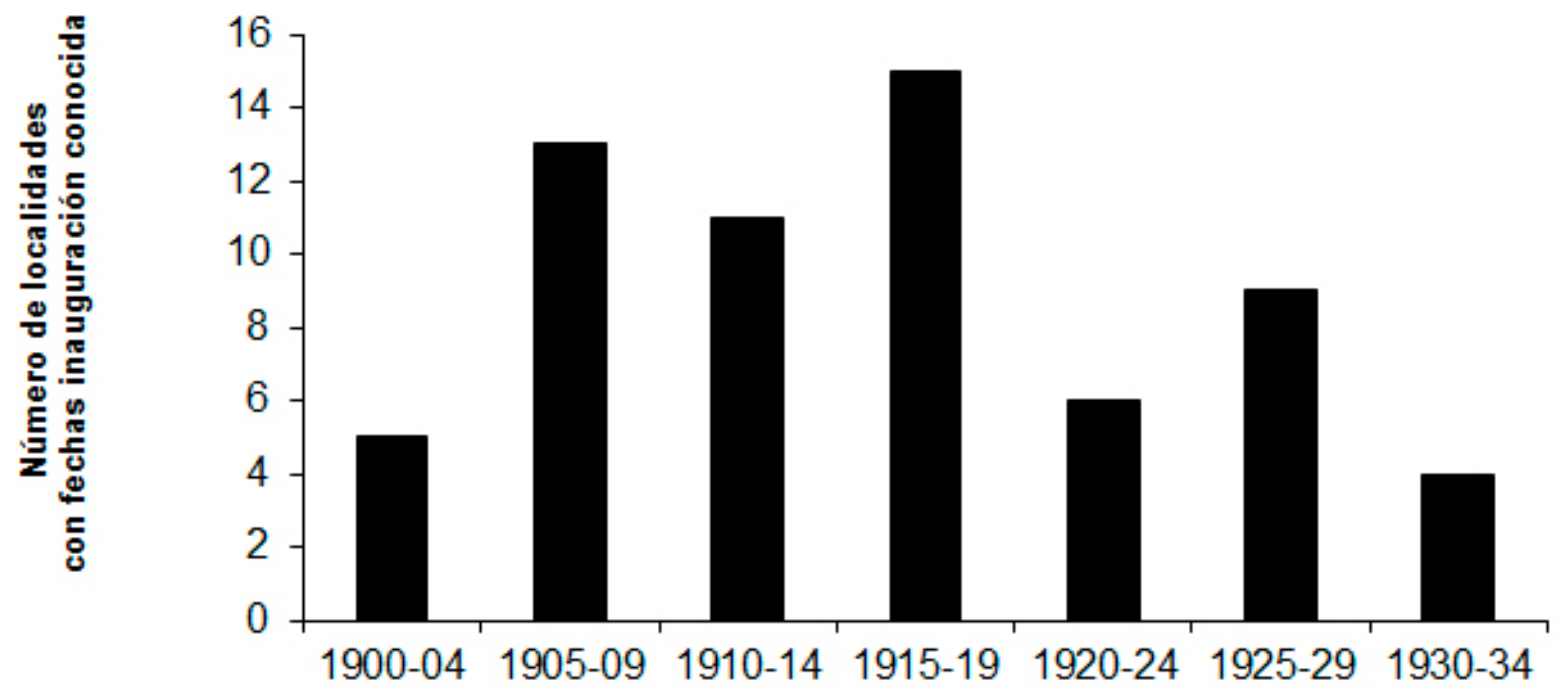

Fuente: Anexo 1

los cinco años, la distribución de frecuencias de la Figura 4 reconstruiría la cronología de la implantación de las Gotas de Leche en España hasta 1936. Estos resultados vendrían a sugerir una reducción menos marcada en la difusión de estos centros a partir de la década de los años 20 que la observada previamente en la Figura 3. La Tabla 4 confiere a este despliegue una perspectiva territorial (representada además en la Figura 5). Aquí puede apreciarse una cierta secuencia regional en el mismo. En los primeros quince años del siglo XX, las Gotas de Leche se implantan preferentemente en el norte peninsular, acompañado de los territorios del interior (ambas Castillas y León). A partir de 1920, los nuevos centros parecen haberse expandido más en la zona Mediterránea, Norte de África (territorios del protectorado en Marruecos ${ }^{14}$ ) y el sur (Extremadura y Andalucía). Como deja entrever la lectura numérica de esta trayectoria en la última columna de la Tabla 4, la tasa de crecimiento de la frecuencia acumulada de establecimientos activos se comportaría con una clara tendencia descendente, rasgo básico observable en procesos de de difusión social e institucional. En cualquier caso, 79 localidades no equivalen al total de centros que llegarían a abrirse en España hasta 1936. Parece que, al menos, esta cifra se debería aproximar a los 90, si sumamos los mencionados en las fuentes y la historiografía para ciudades como Barcelona (3), Bilbao (3), Jaén (2), Madrid (3), Valencia (2), Sevilla (2) y Zaragoza $(2)^{15}$. 
Figura 4. Cronología Gotas de Leche Activas

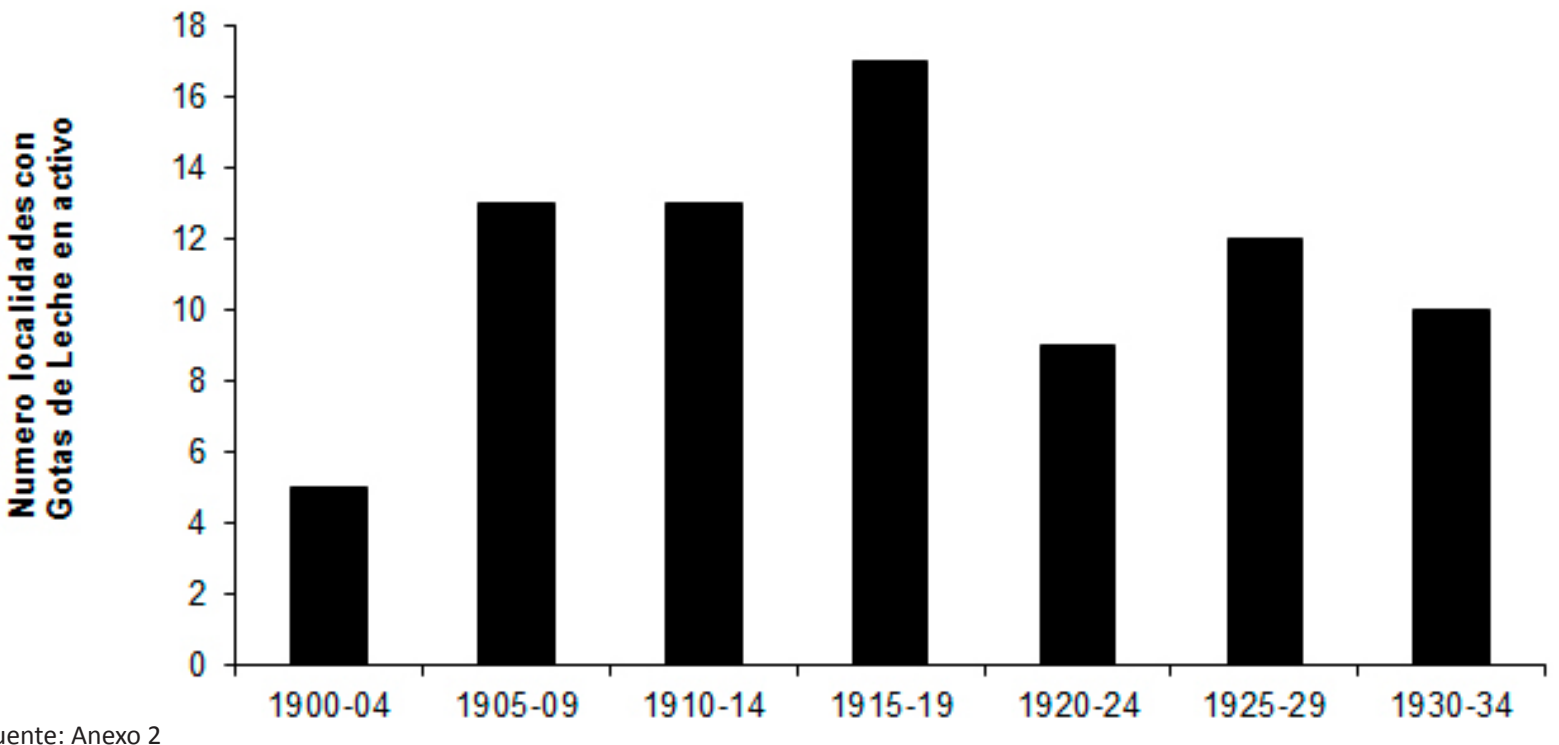

Tabla 4. Frecuencia y distribución geográficas Gotas de Leche Activas

\begin{tabular}{|c|c|c|c|c|c|c|c|c|}
\hline Períodos & Norte & Mediterráneo & Interior & Sur & $\begin{array}{l}\text { Norte } \\
\text { Africa }\end{array}$ & Total & Total Acumulado & $\begin{array}{c}\text { Tasa crecimiento } \\
(\%)\end{array}$ \\
\hline $1900-04$ & 2 & 1 & 2 & 0 & 0 & 5 & 5 & \\
\hline 1905-09 & 3 & 3 & 4 & 3 & 0 & 13 & 18 & 25,6 \\
\hline $1910-14$ & 4 & 2 & 4 & 3 & 0 & 13 & 31 & 10,9 \\
\hline $1915-19$ & 3 & 4 & 5 & 4 & 1 & 17 & 48 & 8,7 \\
\hline $1920-24$ & 1 & 0 & 1 & 4 & 3 & 9 & 57 & 3,4 \\
\hline $1925-29$ & 1 & 5 & 1 & 5 & 0 & 12 & 69 & 3,8 \\
\hline $1930-34$ & 0 & 3 & 3 & 4 & 0 & 10 & 79 & 2,7 \\
\hline
\end{tabular}

Norte= Galicia, Asturias, Pais Vasco, Navarra y Aragón. Mediterráneo= Cataluña, Baleares, Valencia y Murcia

Interior= Castilla la Vieja, León, Castilla la Nueva. Sur= Extremadura, Andalucía y Canarias

Fuente: Anexo 2

Expresado lo anterior en términos más históricos, estos datos estarían mostrando como antes de la Guerra Civil la expansión de las Gotas de Leche en España podría haber perdido intensidad. Esta última afirmación, no obstante, requiere de matización habida cuenta de los cambios que la propia organización asistencial de la medicina de la infancia a lo largo del primer tercio del siglo XX indujeron sobre la atención a los recién nacidos.

Se introdujo en el apartado anterior la distinción entre la reconstrucción de la difusión de la institución y el seguimiento de la intensidad de su actividad. La Figura 6 reproduce la distribución cronológica de esta segunda dimensión. Esto es, al recuento de las Gotas de Leches activas expuesto en la Figura 4 se han sumado aquellas otras actividades que en las localidades con estos centros además se han registrado noticias de nuevos actos de expansión, traslado o mejora de sus instalaciones. Existe pues, de acuerdo, a este criterio, un doble cómputo para algunos lugares ${ }^{16}$. De nuevo han quedado excluidas las localidades del Anexo 2 que contaron con propuestas de instalación, pero para las que no ha sido posible verificar alguna actividad posterior. Esta reconstrucción de la intensidad en la actividad en lo esencial replica la cronología de las Figuras 3 y 4, pero introduce una variación de interés, cono es el repunte de actividad observable en el quinquenio 1925-29. Situado en lo que parecería ser una fase cronológica de reducción en la apertura de nuevos establecimientos según se muestra en la Figura 3, podría interpretarse como manifestación de una etapa de consolidación y mejora de la calidad del servicio. En cualquier caso, se trataría de una primera hipótesis que investigaciones posteriores deberán contrastar. 
Figura 5. Cronología de actividad de Gotas de Leche por grandes Regiones

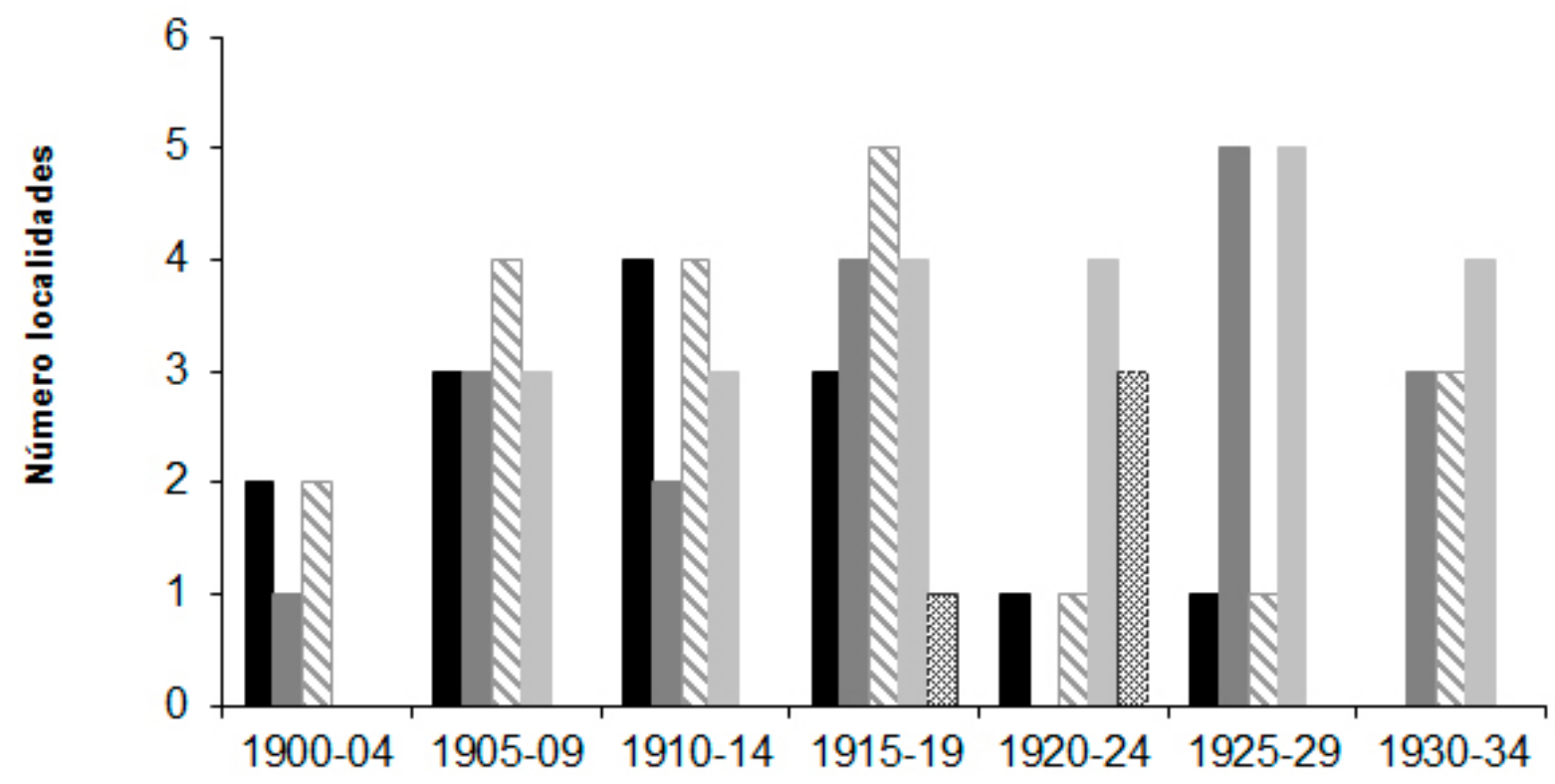

\begin{tabular}{|lll|}
\hline Norte $\quad$ Mediterraneo & alnterior & Sur $\quad$ Norte Africa \\
\hline
\end{tabular}

Fuente: Tabla 4.

Figura 6. Cronologia de la intensidad en la actividad de las Gotas de Leche

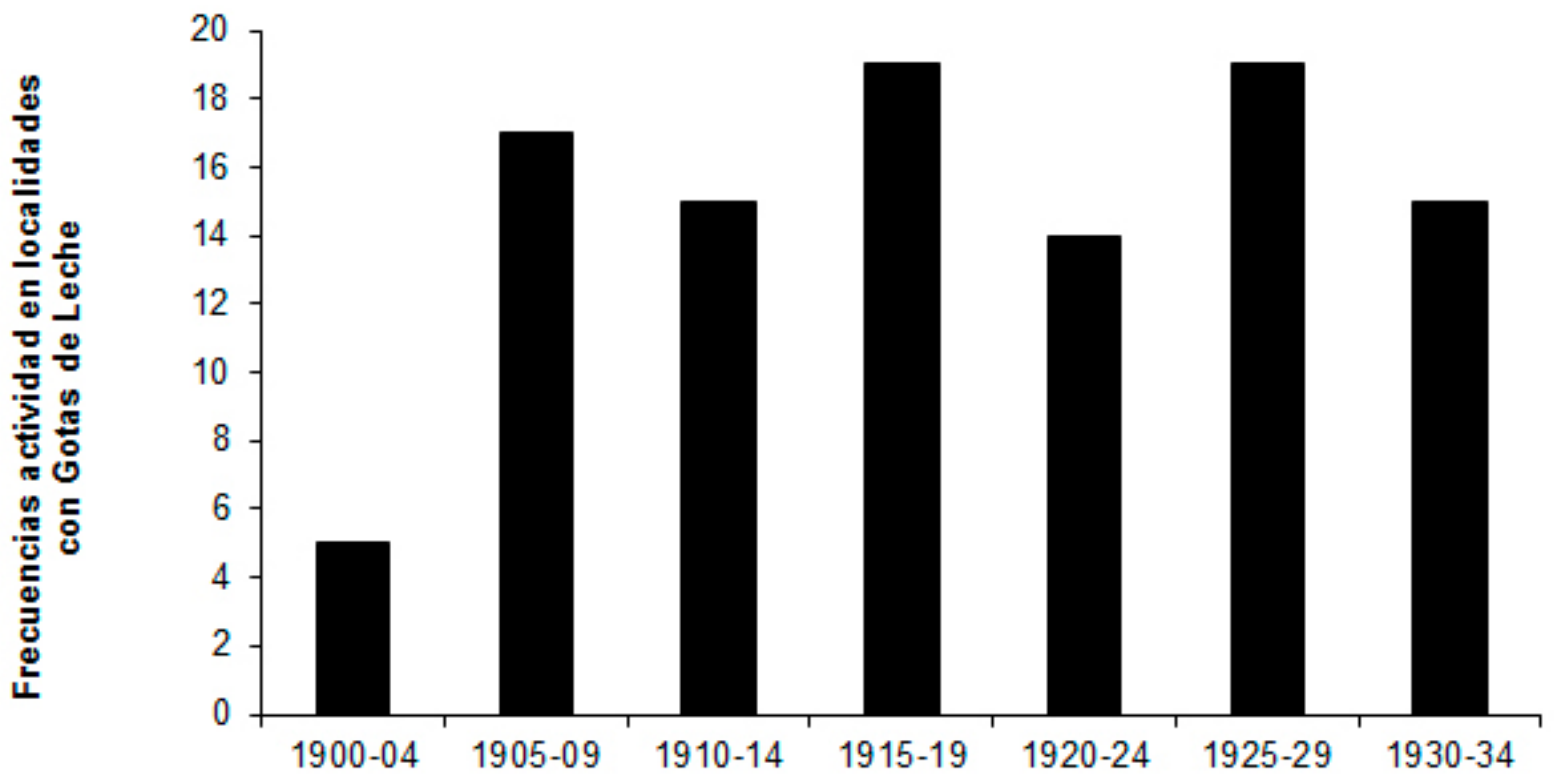

Fuente: Anexo 2. 
La mayoría de los establecimientos de los que tenemos noticia se abrieron en ciudades, principalmente, capitales de provincia. Según los datos recogidos, hacia 1915, de las 32 instituciones de esta clase existentes en España, 23 correspondían a localidades con esta condición ${ }^{17}$. Así, podría ser útil, a fin de entender el patrón inicial de difusión de esta institución en España, comparar algunas características de las ciudades que contaban con estos centros respecto aquellas que no disponían de los mismos antes de 1915. La Tabla 5 recoge algunos indicadores que tratan de evaluar la relación entre la fundación de Gotas de Leche con factores de localización relevantes. Estarían relacionados con aspectos que de manera más directa podrían contribuir a la apertura de un centro como el nivel de urbanización, las condiciones de mortalidad infantil, las de la fecundidad, la organización sanitaria o la existencia de corporaciones beneficencia.
Todos ellos se representa a través de 11 variables en la mencionada tabla donde para cada una se presentan los valores medios, el máximo y el mínimo y el coeficiente de variación. Además, en la última columna, se evalúa estadísticamente la diferencia de medias entre ambos bloques de capitales. Este criterio estadístico puede ayudar a discriminar la relevancia de los distintos factores de localización propuestos.

De acuerdo a los resultados, se constata como las variables ligadas al peso proporcional de las mujeres casadas, el mayor tamaño de las localidades en el total de la provincia, el nivel de alfabetización y, finalmente, un mayor grado de actividad en las organizaciones benéficas, parecerían estar más asociadas con la apertura de estos establecimientos antes de 1915 . En cambio, no tendrían igual relevancia, los niveles de mortalidad infantil, ni las condiciones demográficas de la población femenina (fecundidad y peso de las mujeres en edad fértil casadas), ni la disponibilidad de recursos sanitarios.

Tabla 5. Indicadores de localización de las Gotas de Leche en capitales de provincia circa 1915

\begin{tabular}{|l|c|c|c|c|c|c|c|c|c|}
\hline \multirow{2}{*}{ Indicadores } & \multicolumn{4}{|c|}{ Con Gotas Leche } & \multicolumn{3}{c|}{ Sin Gotas Leche } & Diferencia \\
\cline { 2 - 10 } & Media & CV & Máximo & Mínimo & Media & CV & Máximo & Mínimo & $\begin{array}{c}\text { Estadístico } \\
\text { "t" } \\
\text { nivel sig } \mathbf{p}\end{array}$ \\
\hline Coeficiente de Urbanizacion-Municipio & 37,95 & 0,73 & 90,70 & 3,80 & 35,24 & 0,70 & 89,60 & 4,70 & 0,640 \\
\hline Población Total & 111.283 & 1,46 & 599.807 & 12.176 & 32.786 & 0,64 & 80.511 & 7.535 & n.a \\
\hline $\begin{array}{l}\text { \% Capital (21-35)/Provincia(21-35) } \\
\text { Casadas }\end{array}$ & 18,11 & 0,86 & 65,39 & 3,31 & 7,77 & 0,57 & 22,79 & 3,30 & $0,005^{*}$ \\
\hline $\begin{array}{l}\text { Casadas Capital/ Total casadas capital } \\
\text { España }\end{array}$ & 3,31 & 1,52 & 20,07 & 0,31 & 0,92 & 0,65 & 2,23 & 0,20 & $0,033^{* *}$ \\
\hline Médicos por mil habitantes & 3,11 & 0,35 & 5,06 & 1,01 & 2,90 & 0,31 & 4,89 & 1,22 & 0,475 \\
\hline Índice de Fecundidad General & 0,31 & 0,15 & 0,41 & 0,23 & 0,32 & 0,22 & 0,45 & 0,14 & 0,627 \\
\hline Tasa de Mortalidad Infantil & 171,48 & 0,25 & 298,50 & 95,00 & 189,38 & 0,23 & 316,00 & 125,50 & 0,156 \\
\hline $\begin{array}{l}\text { Tasa Mortalidad por Diarrea y Enteritis } \\
\text { (<2 años) }\end{array}$ & 70,19 & 0,43 & 171,88 & 32,09 & 83,30 & 0,41 & 139,89 & 34,39 & 0,164 \\
\hline Proporción Mujeres Alfabetizadas & 65,68 & 0,24 & 86,40 & 28,95 & 56,87 & 0,26 & 87,74 & 34,55 & $0,053^{* * *}$ \\
\hline $\begin{array}{l}\text { Ratio Fundaciones Beneficencia } \\
\text { Activas/Inactivas }\end{array}$ & 2,30 & 0,85 & 8,07 & 0,42 & 1,25 & 0,93 & 5,93 & 0,18 & $0,033^{* *}$ \\
\hline Fundaciones por 10.000 habitantes & 6,58 & 0,84 & 21,97 & 1,25 & 5,14 & 0,84 & 18,30 & 0,69 & 0,320 \\
\hline
\end{tabular}

$\mathrm{CV}=$ Coeficiente de Variación. N.a= No aplicado. $\mathrm{p}=$ probabilidad para dos colas $* p \leq 1 \% * * p \leq 5 \% * * * \leq 10 \%$ Indicadores y fuente:

(Coeficiente de Urbanizacion-Municipio) Proporcion localidades > 5000 habitantes en la provincia (Luna Rodrigo, 1984). (Población Total). Capitales Provincia.Censo de Población de 1910.( \% Capital (21-35)/Provincia(21-35) Casadas): Porcentaje mujeres casadas entre 21 y 35 años en la capital en el mismo grupo de edad y estado civil de la provincia. Censo de Población 1910. (Casadas Capital/ Total casadas capital España). Porcentaje mujeres casadas en la capital de provincia en el total de mujeres casadas residentes en capitales de provincia en España en 1910. (Médicos por mil habitantes (en las capitales de provincia)). Estadísticas de profesiones Censo de Población de 1910. (Indice de Fecundidad General). Estimado según metodología de A. Coale, a partir datos del Movimiento Natural de la Población 1909-1911 y Censo de Población 1910. (Tasa de Mortalidad Infantil) Capitales de provincia 1914-1915. (Arbelo, 1962). (Tasa Mortalidad por Diarrea y Enteritis (<2 años)) Calculada a partir Movimiento Natural de la Población 1913-15. (Proporcion Mujeres Alfabetizadas) Capital de provincia. A partir del Censo de Población de 1910 (Ratio Fundaciones Beneficencia Activas/Inactivas) y (Fundaciones por 10.000 habitantes). Calculadas a partir de datos publicados en el Anuario Estadístico de España 1910-1911 y Censo de Población de 1910. 
Conviene observar que 13 de las 23 capitales de provincia con Gotas de Leche activas antes de 1915 contaban con más de cincuenta mil habitantes y 7 de las 13 más de cien mil. Esto explica la apreciable diferencia en las medias de población de ambos conjuntos de localidades estimadas en la Tabla 5. Así, sí estas instituciones fueron creadas bajo el impulso de iniciativas locales, parece que aquellas ciudades con un mayor tamaño podían movilizar recursos sanitarios más fácilmente que el resto. Sin que una mayor frecuencia de médicos por mil habitantes resultara necesariamente un buen indicador al respecto. Más que el número, sería la capacidad de la profesión médica local para generar un estado de opinión que juzgara como insostenibles los niveles de mortalidad infantil, lo que habría supuesto una diferencia significativa en aquellas primeras décadas del siglo. Como bien muestran los estadísticos sobre la mortalidad infantil en la Tabla 5, las ciudades que implantan las Gotas de Leche antes de 1915, con un coeficiente de variación semejante a las que no lo hicieron, tenían en promedio menor mortalidad.

Cabe recordar aquí que las grandes urbes como Barcelona, Bilbao, Madrid, Sevilla y Valencia habían impulsado cambios en sus organizaciones sanitarias desde el decenio de 1880, por ejemplo, construyendo edificios para laboratorios municipales o nuevos hospitales, algunos específicamente destinados a la población infantil. Sin olvidar la presencia de Facultades de Medicina en la mayor parte de ellas. Estas ciudades de mayor tamaño habrían actuado como centros de difusión de nuevas metodologías sanitarias en la lucha contra la mortalidad infantil. Se trataba de una tarea promocionada tanto por instituciones pública, privadas o por personalidades médicas.

De acuerdo a la información detectada en la prensa, la profesión médica jugó un papel destacado en los inicios de la implantación de las Gotas de Leche en España. El doctor Rafael Ulecia podría considerarse como el ejemplo paradigmático de la difusión de las Gotas de Leche a través del contacto personal y la ejemplaridad profesional. Su influencia fue abiertamente reconocida por los contemporáneos. La prensa de la época ofrece múltiples testimonios. Por ejemplo, en Pamplona, donde en una visita suya el año 1905 al consultorio creado por la organización benéfica "La Conciliación» declara al «El Eco de Navarra» (15 Octubre) que «no le falta más que el complemento de la Gota de Leche». En Talavera de la Reina, la Gota de Leche se abrió en 1906, promovida por su alcalde, médico de profesión, que en una visita anterior a Madrid había invitado al doctor Ulecia a su inauguración («El Criterio», 2 Junio
1906). Ese mismo año, en el número del 8 de septiembre de la revista semanal «Flores y Abejas», se informa que el doctor tiene el propósito de establecer un consultorio en Guadalajara «a la que se propone venir todos los domingos». Años más tarde, en 1911, firmará una carta en apoyo del acuerdo del Ayuntamiento de fundar "Consultorio de Niños de Pecho y Gota de Leche» en esa ciudad. Además, en los casos de Segovia (1909), Oviedo (1911) o Murcia (1913) sus promotores reconocen públicamente la inspiración o influencia de su obra médica e institucional.

Otro ejemplo de influencia profesional en la apertura de estos centros lo representó el Dr. Martínez Vargas, catedrático de Pediatría en la Universidad de Barcelona. El mismo, habría desempeñado un papel en la apertura de la Gota de Leche de Palma de MaIlorca. El Dr. José Mir, ex alumno suyo, fue uno de sus promotores el año 1916 y visitó Barcelona y los servicios municipales de lactancia acompañado de quien había sido su profesor (Montilla y Sureda, 2008, pp. 172-196). De igual modo estaría relacionado con el establecimiento de la Gota de Leche de Lérida, donde ya había impulsado las «Pólizas de protección infantil» de 1902 (Samper, 2004, p. 355) y en la que pronuncia la conferencia inaugural («La Medicina de los Niños», Julio 1919). El pediatra aragonés fue el promotor de la apertura del Instituto Nipiológico de Barbastro (1916), la localidad de la que era originario (Loste, 1933).

El papel de los médicos en la creación de las Gotas de Leche puede ilustrarse con otros ejemplos, recogidos en la prensa. En Segovia donde, según el «Diario de Avisos» del 16 de Marzo 1909, un médico, sin especificar nombre alguno, la impulsa. Málaga, implantada como consecuencia de una conferencia del Dr. Huertas Lozano ( $A B C »$, Noviembre 1906). En Alicante, creada a propuesta del Dr. Carlos Manero Pineda ( $\mathrm{EI}$ Luchador», 2 Octubre 1925); Granada, impulsada por el Dr. García Duarte (Rodríguez Ocaña y García-Duarte Ros, 1984); Guadalajara, establecida y sostenida, al parecer, personalmente por el Dr. Enrique Ballesteros («Flores y Abejas», 24 Noviembre 1911); Gijón, por iniciativa del Dr. Avelino González (Fernández Menéndez, 2014); Santander, donde el Dr. Pablo Pereda Elordi la pondrá en marcha en 1905 en la Casa de la Caridad después que el Ayuntamiento le negara un solar para construir un edificio "por suscripción popular» (Fernández Teijeiro, 2014, p.30); Orense, bajo la iniciativa del médico Lino Porto Porto, «fundado por su cuenta»(«El Noroeste», 10 Junio 1911) y Sevilla, resultado de la iniciativa del médico Ciriaco Esteban García, («ABC»Sevilla, 4 Diciembre de 1934). 
Otra de las vías de difusión de esta institución consistió en lo que vendría a ser el «efecto de demostración» que la apertura de una Gota de Leche podía suponer sobre las localidades cercanas. Un ejemplo ilustrativo sería la serie de inauguraciones en ciudades del País Vasco y territorios aledaños. La creación de una Gota de Leche en San Sebastián el año 1903 parece influir en la de Logroño de 1904, ésta, a su vez, en la de Vitoria según se relata en el "Heraldo Alavés» del 30 de Enero de 1912. Allí, rememorando los orígenes de la institución, se escribe: "tomamos la idea de la Gota de Leche de una moción presentada por un alavés al municipio de Logroño». El alcalde y el secretario de Tolosa visitan en 1904 la de San Sebastián («Eco de Navarra», 8 Noviembre 1904). Un año antes, han realizado una visita informativa a la capital donostiarra un médico y un concejal de Pamplona («Heraldo Alavés», 16 Noviembre 1903). También lo hacen el mismo año "comisionados» de Bilbao, Santander "y otros puntos de España» según indica el «Eco de Navarra» del 21 de octubre de 1903.

\section{GOTAS DE LECHE: CREACIÓN Y ORGANIZACIÓN}

La creación de estos centros debe situarse en el contexto de la formación de la moderna administración sanitaria en España. Esta administración fue desarrollada por leyes aprobadas en la segunda mitad del siglo XIX que diseñaron una organización jerárquica en tres niveles: el central, el provincial y el local (Muñoz Machado, 1975, pp. 99-125; Rodríguez Ocaña y Martínez Navarro 2010, pp. 44-47, 60-66). Lógicamente, la Ley de Infancia de 1904 las adoptó y así en el posterior desarrollo reglamentario de 1908, distinguió entre el Consejo Superior de Protección de la Infancia (presidido por el Ministro de Gobernación), las Juntas Provinciales y las Locales (Ministerio de Gobernación 1908). Estructurado el mencionado Consejo en secciones una atendía específicamente a los problemas de la alimentación infantil (Puericultura y primera infancia) aunque básicamente orientado a la vigilancia de la lactancia mercenaria. En cualquier caso, el establecimiento de Gotas de Leche no quedó contemplado específicamente en ninguna de estas normas. Parece que es necesario esperar hasta la segunda mitad de la década de 1920, con la publicación de distintos tipos de normativa sanitaria y administrativa a escala local (Perdiguero 1997), para que se mencione explícitamente la creación de Gotas de Leche como una de las secciones de los Institutos de Puericultura a establecer en cada capital ${ }^{18}$. Por tanto, durante gran parte del período aquí estudiado la administración sanitaria española no promovió, al menos formalmente, un plan general para implantar estos centros.
En este contexto, la apertura de Gotas de Leche resultó de una combinación de iniciativas diversas. Estas involucraron a las instancias administrativas creadas por la legislación sanitaria vigente pero también a instituciones benéficas diversas e, incluso, a ciudadanos a título personal. De este modo, no puede llamar la atención que todo el proceso de decisión que conducía a su apertura pudiera resultar azaroso. Tres fases lo caracterizarían, a saber: 1a La iniciativa y movilización a favor de la institución 2a . La localización y organización del servicio 3a La asignación de recursos materiales y financieros para su puesta en marcha. Tanto la documentación periodística consultada, como los estudios monográficos publicados, permiten apreciar las circunstancias y complicaciones diversas involucradas en todo este proceso de toma de decisiones.

Una de las manifestaciones objetivas de aquellas dificultades sería el lapso de tiempo transcurrido hasta la apertura de una Gota de Leche. Datos precisos sobre esta secuencia temporal sólo se han podido reunir para 22 localidades. En la Tabla 6 se distingue entre dos periodos, uno, el transcurrido desde la presentación de una primera propuesta, el otro, desde el acuerdo oficial de su establecimiento. Aunque el número de observaciones es escaso y, por tanto, los rasgos de variación de las duraciones notables algunas características pueden señalarse. Así, para el cómputo a partir de la propuesta inicial, donde en 6 de 12 casos, supera los cuatro años, alcanzando incluso en una de las localidades como Tortosa casi los veintisiete años. Como cabía esperar, cuando se trata del tiempo invertido desde el acuerdo, el plazo resultó menor. Aquí, en 11 de 15 casos, fue igual o menor a dos años. Pero en Badajoz, la dilación fue extrema, al sucederse acuerdos y revocaciones, necesitando de casi 20 años hasta la inauguración.

La obvia implicación de esta disparidad en los ritmos de apertura es que no todas las decisiones debían culminar necesariamente en la puesta en marcha de una nueva Gota de Leche. Las secuencias más plausibles en las que un acuerdo inicial favorable no llegaba a prosperar habrían sido dos. Una, en la que la decisión simplemente se revocaba más tarde y, la otra, en la que se ponían de manifiesto dudas o reparos que culminaban en el abandono final del proyecto. Además, la consulta de las fuentes periodísticas revela casos en los que estos centros habrían cerrado definitivamente o interrumpido su actividad por un largo tiempo. Veamos a continuación algunos ejemplos.

En Santa Cruz de Tenerife, menciona un artículo publicado en 1915, se estableció una Gota de Leche «hace unos años», pero a los pocos meses, «la abandonaron 
sus patrocinadores y la volvió también la espalda el público» («La Prensa», 12 Octubre 1915). Al parecer, de acuerdo al recuento de R.Ulecia (1912) en 1907 estaba abierta pero no en el momento de redactar su informe, probablemente hacía 1910. En 1917, la Junta Provincial de Protección de la Infancia y la Mendicidad estudia un acuerdo, pero en 1920 continúa la presentación de propuestas. No se ha encontrado ninguna información sobre la recuperación de este centro, si bien un artículo publicado en 1932 deja constancia de la aprobación de una partida municipal «para leche a los niños pobres» («La Prensa», 27 Noviembre 1932). En Pamplona, la Gota de Leche creada en 1916 se suprime en 1935 (Anaut Bravo, 1999, p. 38). En Guadalajara, el movimiento de apoyo y petición iniciado el 1906 parece culminar en 1911 con una serie de acuerdos para la apertura del establecimiento. Así, en Junio de aquel año se informa («La Región», 9 Junio 1911) de la aprobación por el Gobierno civil del reglamento del «Consultorio del Niño de Pecho y Gota de Leche». Pero a finales del mismo año, la prensa hace público el fracaso en la constitución de la Junta de Damas del consultorio ("Flores y Abejas»,24 Noviembre 1911) y en una carta al director, el mismo Dr. Ballesteros da a entender que él asume en solitario la apertura del centro. Así "La Región» informa el 15 de diciembre de 1911 que los domingos este facultativo vacuna gratuitamente a los niños en el local de la Gota de Leche. Probablemente esta actividad continuó, pero no se han encontrado noticias en la prensa local al respecto.

De hecho, la revista "Flores y Abejas» publica el 4 de Abril de 1920 el titular "Se acabó la Gota de Leche», donde se mencionan dificultades financieras que no permiten sostenerla. Será en 1926, cuando bajo iniciativa directa del Gobierno Civil, se establezca en la planta baja del Ayuntamiento («Flores y Abejas», 21 Marzo

Tabla 6. Tiempo transcurrido en la inauguración de Gotas de Leche en España

\begin{tabular}{|c|c|c|c|c|c|c|c|c|}
\hline \multirow[t]{2}{*}{ Localidad } & \multicolumn{2}{|c|}{$\begin{array}{l}\text { Primera propuesta o } \\
\text { demanda de centro }\end{array}$} & \multicolumn{2}{|c|}{$\begin{array}{c}\text { Acuerdo oficial de instalación } \\
\text { de la Gota de Leche }\end{array}$} & \multicolumn{2}{|c|}{ Inauguración } & \multicolumn{2}{|c|}{$\begin{array}{c}\text { Tiempo transcurrido en años } \\
\text { y fracción }\end{array}$} \\
\hline & Año & Mes & Año & Mes & Año & Mes & Propuesta & Acuerdo \\
\hline Ciudad Real & & & 1916 & Enero & 1922 & Julio & & 6,5 \\
\hline Tarragona & 1904 & Agosto & 1911 & Marzo & 1918 & Junio & 13,8 & 7,3 \\
\hline Reus & 1914 & Marzo & 1917 & Setiembre & 1919 & Enero & 4,8 & 1,3 \\
\hline Tortosa & 1903 & Agosto & & & 1930 & Junio & 26,8 & \\
\hline Alicante & 1914 & Mayo & 1923 & Diciembre & 1925 & Octubre & 15,3 & 1,8 \\
\hline Oviedo & & & 1912 & ¿? & 1913 & ¿? & & 1,0 \\
\hline Vitoria & & & 1904 & $\dot{2} ?$ & 1906 & Abril & & 2,0 \\
\hline Palencia & & & 1917 & Febrero & 1918 & Julio & & 1,5 \\
\hline Pamplona & 1908 & Abril & & & 1916 & ¿? & & 8,0 \\
\hline Murcia & 1912 & Noviembre & & & 1913 & Abril & 0,4 & \\
\hline Palma Mallorca & 1906 & Agosto & & & 1907 & Enero & 0,4 & \\
\hline Mahón & 1905 & Agosto & & & 1906 & ¿? & 1,0 & \\
\hline Badajoz & & & 1906 & Julio & 1926 & Enero & & 19,5 \\
\hline Bilbao & & & 1906 & Octubre & 1907 & Agosto & & 0,8 \\
\hline Cádiz & 1914 & Julio & & & 1916 & Enero & 1,5 & \\
\hline Córdoba & 1909 & ¿? & & & 1919 & Abril & 10,0 & \\
\hline La Coruña & 1911 & Octubre & & & 1912 & Mayo & 0,6 & \\
\hline León & 1929 & ¿? & 1933 & Marzo & 1934 & Febrero & 5,0 & 0,9 \\
\hline Lérida & & & 1916 & Setiembre & 1918 & Diciembre & & 1,2 \\
\hline San Sebastián & 1901 & Octubre & 1902 & Agosto & 1903 & Septiembre & 0,8 & 1,1 \\
\hline Huelva & 1921 & Mayo & 1922 & Junio & 1924 & ¿? & 1,1 & 2 \\
\hline Gijón & & & 1922 & Junio & 1925 & Septiembre & & 2,25 \\
\hline
\end{tabular}

Fuente: BVPH, excepto para San Sebastián(Junta Adminsitradora Gota de Leche (1953)) , Huelva ( Segovia Azcárate,1995) y Gijón (Fernández Menendez, 2014). 
1926). Una peripecia semejante acontece en el caso de la Gota de Leche de Badajoz. Desde la publicación de un artículo a favor de este centro, publicado en 1906 («Noticiero extremeño», 17 Julio 1936), hasta la entrega del edificio en 1925 y la puesta en servicio el año siguiente, se suceden en 1906, 1910 y 1914 pronunciamientos favorables, para constatarse, según la prensa de la época, que en 1916, todavía sigue sin inaugurarse, no contando, al parecer, ni siquiera con apoyo municipal ("La Región Extremeña»,8 Marzo 1916).

En otras ocasiones, las propuestas iniciales a favor parece que no culminaron como sería el caso de Soria. En 1915 registró una primera iniciativa impulsada por el Gobernador civil («El Porvenir Castellano»,15 Enero 1915) pero en 1930 continuaba elaborando un presupuesto para su inauguración («Noticiero de Soria», 17 Julio 1930). En Gerona en 1910 («Heraldo de Gerona»,1 Diciembre 1910) y en Santiago Compostela en 1912 («El Noroeste», 26 de Septiembre 1912) y 1915 («El Noroeste», 3 Septiembre 1915) la prensa local publicó noticias sobre iniciativas semejantes que, de nuevo, no parece cristalizaran en establecimiento alguno.

Pero este recuento de procesos incompletos o frustrados no debe llevar a inferir que aquellos que si culminaron estuvieron exentos de tensiones ${ }^{19}$. Está más allá del espacio reservado a este artículo explotar exhaustivamente una información para la que las fuentes de la prensa diaria local pueden considerarse muy apropiadas. Sirva como ejemplo el caso de la Gota de Leche de Vitoria, inaugurada en abril de 1906. Estuvo precedida de un dictamen favorable del consistorio en 1904 ( «Heraldo Alavés», 23 Junio de 1904) en base a una memoria redactada por el jefe del laboratorio municipal. Pero, a partir de entonces se originó una discusión entre las fuerzas políticas, «la oposición no ve necesidad de hacer un edificio «ad hoc» («Heraldo Alavés», 12 Diciembre 1904). De este modo, acabó instalándose en la planta baja del Casino Artista. La búsqueda de una nueva ubicación y el financiamiento se convirtieron en un tema recurren- te en la prensa a lo largo de las dos décadas siguientes. Así se entienden las mociones municipales del año 1920 («La Libertad»,13 Noviembre 1920), con precedentes en los años 1910, destinadas a establecer una vaquería al servicio de la Gota de Leche, o el comentario publicado en "La Libertad» el 29 de Marzo de 1919, en el que el proyecto del gobernador civil de abrir un Dispensario Antituberculoso fundado por la Cruz Roja en un nuevo edificio en el sentido de que «si se inaugura [aquel local] la Gota de Leche se fusionará con él». En 1922 el diario «La Libertad» del 22 de Marzo se hace eco de distintos traslados de dependencias municipales y de reubicación de establecimientos escolares, sugiriendo el periodista la conveniencia de hacer lo mismo con de la Gota de leche, "se hará un gran favor al Casino del Artista y no hay necesidad de estar como de prestado». Será necesario esperar hasta 1927 para la mudanza a una dependencia del Hospital de Santiago de la ciudad (noticia publicada en el «Heraldo Alavés» el 16 julio de 1927).

Dadas, pues, la variedad de dinámicas implicadas en la implantación de estos centros no puede extrañar que los perfiles institucionales de los mismos resultaran, así mismos, variados. En la Tabla 7 se ilustra este punto. Los datos reunidos corresponden a 61 establecimientos de los que se cuenta información sobre este aspecto. En este conjunto de localidades, un 55 por ciento de las Gotas de Leche habrían sido creadas y eran controladas por la Administración, sea a través de los propios ayuntamientos o de las correspondientes Juntas de Protección a la Infancia. Un 28 por ciento responderían a las iniciativas de particulares (como se mencionó en el apartado anterior, con una presencia activa de médicos) y/o de organizaciones de caridad. Finalmente, una menor proporción -el 18 por ciento- sería de naturaleza "mixta», esto es resultado de la participación de iniciativa privada y soporte público. Es importante observar en este punto que este conjunto de situaciones describen las condiciones al inicio de las trayectorias de estos centros, no los cambios que en relación a las mismas pueden haber tenido lugar más tarde.

Tabla 7. Naturaleza del establecimiento de las Gotas de Leche inauguradas 1900-1935

\begin{tabular}{lcc}
\hline Institución pertenece & Número & Porcentaje \\
\hline Ayuntamiento & 18 & 29,5 \\
\hline Juntas Proteccion Infancia & 15 & 24,6 \\
\hline Organización Caridad & 13 & 21,3 \\
\hline Iniciativa privada/Org. Caridad y/o Administración & 11 & 18,0 \\
\hline Iniciativa privada y/o org caridad & 4 & 6,6 \\
\hline Total & 61 & 100 \\
\hline Fuente: BVPH
\end{tabular}


El peso de las condiciones locales en la organización de los establecimientos acabaría reflejándose en distintos aspectos. La Tabla 8 reúne para seis localidades algunos indicadores que permiten ilustrar con más detalle este punto ${ }^{20}$. Pretenden reflejar cierta tipología de las formas de organización, que investigaciones posteriores deberían confirmar en qué medida podría considerarse representativa. Así, en primer lugar, como ya se había visto antes, desde el punto de vista institucional se distinguirían dos tipos de Gotas de Leche, las públicas y las privadas. Las primeras habrían sido financiadas por los municipios. Estos proporcionaban personal médico y otros recursos materiales, particularmente, los edificios. Esta situación parecería ser la propia de grandes zonas urbanas, como el caso de Madrid y Barcelona. Las segundas, eran fruto de iniciativas apoyadas por instituciones de beneficencia y promovidas por alguna personalidad médica. El centro impulsado por el Dr. Ulecia en Madrid sería un ejemplo al respecto. Una variante de la anterior habría sido la Gota de Leche que, a partir de una iniciativa privada, recibió el apoyo de otros grupos sociales y/o de la administración pública, que se incorporaba más tarde, a través de una ayuda financiera parcial. Así habría ocurrido en Mahón, Reus y Zamora. Ahora bien, la observación de la tabla también permite apreciar como no parece existir una necesaria correspondencia entre la titularidad o naturaleza jurídica del establecimiento y su financiamiento.

Con excepción de los centros municipales de Madrid y Barcelona que al parecer pudieron contar con un soporte presupuestario pleno de sus ayuntamientos, la información disponible sugiere que otros combinaron, tanto a los presupuestos públicos como a las aportaciones privadas, para mantener saneadas sus cuentas. Noticias de tensiones presupuestarias se publicaban en la prensa. Ejemplos de estas dificultades podrían citarse para las Gotas de Leche de Reus y de Alicante. En la primera, donde el Ayuntamiento cuenta desde un principio como "socio numerario", aunque la impulsora sea una asociación benéfica, se necesitó ayuda de un donante privado para poder abrir las puertas (Arnavat et al., 1995, p. 21). En el caso de Alicante, impulsada por el municipio, entre 1926 y 1935, el 46 por ciento del presupuesto procedió de las recaudaciones de bailes benéficos, repetidamente anunciados en la prensa local ${ }^{21}$.

En este contexto, el caso de Zamora reflejaría una situación particular, puesto que, de acuerdo a las informaciones publicadas, parecería ser de los pocos establecimientos sostenidos únicamente por los fondos aportados por la asociación promotora («El Heraldo de Zamora», 31 Enero 1919).

Entre las fuentes de ingresos también se encontraban las aportaciones de usuarios. De nuevo, estas tuvieron lugar con independencia de la naturaleza institucional del centro. Así mismo, se constata como solía tenerse en cuenta su capacidad adquisitiva. Las Gotas de Leche dieron atención prioritaria a las familias pobres, proporcionándoles leche esterilizada y asistencia médica gratuita. Este tipo de atención parece haber sido una característica de los centros de origen municipal, como en los casos de Madrid y Barcelona. Sin embargo, también se planearon los mismos servicios para familias ricas o de otros grupos sociales, que pagaban por ellos. Esta distinción entre las clases sociales de los niños que asisten a la institución se aplicó en Mahón, Reus, Zamora y la clínica del Dr. Ulecia en Madrid. En este último centro las familias ricas y pobres eran visitadas por los médicos en diferentes días de la semana. Por último, debe observarse que todas estas formas de organización y provisión de recursos tienen lugar en contextos de mortalidad y de cobertura de los nacimientos de signo muy diverso, como atestiguan las dos últimas columnas de la tabla.

\section{CONCLUSIÓN}

Este artículo ha presentado una primera aproximación a la reconstrucción de la trayectoria de implantación de las Gotas de Leche en España antes de la Guerra Civil. Con tal fin ha empleado una base documental como las hemerotecas históricas digitalizadas para suplir los límites en la información estadística existente. Aunque las noticias recopiladas, por la naturaleza misma de la fuente, no sean completamente exhaustivas, sí han permitido constatar el despliegue de esta institución, entre 1902 y 1935, en 78 localidades, más otras 8 en las que se presentaron propuestas sin que, al parecer, finalmente prosperaran. En términos de centros, y aunque aquí la contabilidad es más difícil de llevar, la magnitud se aproximaría a las 90 Gotas de Leche. Este primer resultado confirmaría la observación hecha por la historiografía, y por los mismos contemporáneos, respecto a que, la implantación de estos centros en España durante el primer tercio del siglo XX, habría sido más lenta y más limitada en su despliegue que la practicada en las naciones europeas más avanzadas de entonces. En Francia, entre 1907 y 1933 se abrieron un promedio de 168 centros por año de "Consultations nourrissons» (Rollet, 1990,p. 387). En Alemania en 1913, 85 ciudades albergaban 258 centros (Vögele y Woelk, 2002, p. 
Tabla 8. Indicadores de organización y recursos de Gotas de Leche

\begin{tabular}{|c|c|c|c|c|c|c|c|c|}
\hline $\begin{array}{l}\text { Lugar/Año } \\
\text { Inauguracion }\end{array}$ & Habitantes & Fundador & Naturaleza & Gobierno & $\begin{array}{c}\text { Recursos/ } \\
\text { Financiamiento }\end{array}$ & $\begin{array}{l}\text { Ingresados/ } \\
\text { año }\end{array}$ & $\begin{array}{c}\text { Proporción } \\
\text { Nacidos }\end{array}$ & $\begin{array}{c}\text { Tasa } \\
\text { Mor.Inf } \\
\text { por mil }\end{array}$ \\
\hline $\begin{array}{l}\text { Madrid } \\
1904\end{array}$ & $\begin{array}{c}539.835 \\
(1900)\end{array}$ & Dr. Ulecia & $\begin{array}{l}\text { Privada } \\
\text { Org. } \\
\text { Benéfica }\end{array}$ & $\begin{array}{c}\text { Junta } \\
\text { Organización }\end{array}$ & $\begin{array}{c}\text { Donaciones privadas, } \\
\text { Aportaciones } \\
\text { Ayuntamiento } \\
\text { Administración central } \\
\text { Pago usuarios } \\
\text { (diferencias sociales) }\end{array}$ & $\begin{array}{c}804 \\
(1905-09)\end{array}$ & 4,74 & 195 \\
\hline $\begin{array}{l}\text { Madrid, } \\
1913\end{array}$ & $\begin{array}{c}599.807 \\
(1910)\end{array}$ & Ayuntamiento & Pública & Ayuntamiento & Presupuesto Municipal & $\begin{array}{c}594 \\
(1915-19)\end{array}$ & 3,46 & 177 \\
\hline $\begin{array}{l}\text { Barcelona, } \\
\text { 1904/1914 }\end{array}$ & $\begin{array}{c}587.411 \\
(1910)\end{array}$ & Ayuntamiento & Pública & Ayuntamiento & Presupuesto Municipal & $\begin{array}{c}735 \\
(1915-19)\end{array}$ & 7,13 & $\begin{array}{l}157 \\
148\end{array}$ \\
\hline $\begin{array}{l}\text { Mahón, } \\
1906\end{array}$ & $\begin{array}{l}17.144 \\
(1900)\end{array}$ & $\begin{array}{l}\text { Asociación } \\
\text { local }\end{array}$ & $\begin{array}{c}\text { Privada } \\
\text { Org. } \\
\text { Benéfica }\end{array}$ & $\begin{array}{l}\text { Consejo de } \\
\text { directores }\end{array}$ & $\begin{array}{c}\text { Donaciones privadas } \\
\text { Aportaciones } \\
\text { administraciones } \\
\text { públicas } \\
\text { Actividades Benéficas }\end{array}$ & $\mathrm{n} / \mathrm{d}$ & $\mathrm{n} / \mathrm{d}$ & $\mathrm{n} / \mathrm{d}$ \\
\hline Reus, 1919 & $\begin{array}{l}30.266 \\
(1920)\end{array}$ & Dr. Fàbregas & $\begin{array}{c}\text { Privada } \\
\text { Org } \\
\text { Benefica }\end{array}$ & $\begin{array}{l}\text { Consejo de } \\
\text { directores }\end{array}$ & $\begin{array}{c}\text { Donaciones privadas } \\
\text { Aportaciones } \\
\text { administraciones } \\
\text { públicas } \\
\text { Actividades Benéficas }\end{array}$ & $\begin{array}{c}157 \\
(1923-24)\end{array}$ & 30,7 & 121 \\
\hline $\begin{array}{l}\text { Alicante, } \\
1925\end{array}$ & $\begin{array}{l}63.908 \\
(1920)\end{array}$ & Ayuntamiento & Pública & Ayuntamiento & $\begin{array}{c}\text { Donaciones privadas } \\
\text { Aportaciones } \\
\text { administraciones } \\
\text { públicas } \\
\text { Actividades Benéficas } \\
\text { Pago de usuarios } \\
\text { (diferencias sociales) }\end{array}$ & $\begin{array}{c}124 \\
1926-28\end{array}$ & 6,61 & 155 \\
\hline $\begin{array}{l}\text { Zamora, } \\
1916\end{array}$ & $\begin{array}{l}18.185 \\
(1920)\end{array}$ & $\begin{array}{c}\text { Patronato } \\
\text { Org.Caritativa }\end{array}$ & $\begin{array}{c}\text { Privada } \\
\text { Org. } \\
\text { Benéfica }\end{array}$ & Patronato & $\begin{array}{c}\text { Donaciones privadas } \\
\text { Actividades Benéficas } \\
\text { Pago usuarios } \\
\text { (diferencias sociales) }\end{array}$ & $\begin{array}{c}90 \\
1917-20\end{array}$ & 13,68 & 332 \\
\hline
\end{tabular}

Fuente: Datos sobre Fundador, Naturaleza, Gobierno, Recursos e Ingresos año véase nota 18. Poblaciones años 1900,1910 y 1920 de los Censos de Población. Nacimientos de las capitales de provincia del "Movimiento Natural de la Población" en torno año de la inauguración. Nacimientos de Reus estimados a partir de la estadistica de la Generalitat de Catalunya.Departament de Presidència. "Moviments demogràfics i de població de Catalunya". Fascicle 2on.Servei Central di Estadística 1937 pag 98-100. Tasa de mortalidad infantil de las capitales de provincia publicadas en Arbelo (1962). Tasa mortalidad infantil de Reus, calculada a partir información publicada en Arnavat et alt. (1995). 
588), mientras en Inglaterra hacia 1919 se computaban 1278 "Milk Depots», creados desde 1905 a una media 91 establecimientos por año (Wickes, 1953, p. 498). Si bien todas estas magnitudes a fines comparativos deben situarse en el contexto de las cifras de nacimientos de cada país, la diferencia respecto la implantación española continuaría siendo notable. Hacia 1933, año en que se alcanzaría el máximo de Gotas de Leche en Francia, se contabilizarían 61 centros por diez mil nacimientos, mientras en la España de 1935, asumiendo como correcta aquella cifra de 90 establecimientos, tal indicador supondría un exiguo 1,20 centros por cada diez mil nacidos ${ }^{22}$.

Al resultado anterior, y siempre tomando en cuenta las precauciones señaladas respecto la base de datos y la metodología empleada, cabría añadir otros tres como aportaciones principales de esta investigación.

a) Geografía y cronología de su difusión. Las Gotas de Leche se establecen no sólo en una gran mayoría de las capitales de provincia, sino en otras localidades, principalmente con más de 10.000 habitantes. En cualquier caso, parece que no alcanza a cubrir todo el territorio urbano. En seis capitales de provincia no se ha podido constatar una presencia activa de las mismas. Desde un punto de vista cronológico, se ha observado la sucesión de una secuencia completa de expansión y estabilización de aperturas y actividad de estos centros antes de la Guerra Civil. Por otra parte, bajo la influencia de cambios de orientación en la salud pública, las formas iniciales de organización de las Gotas de Leche se habrían ido modificando a favor de nuevas pautas de administración sanitaria, por ejemplo, representadas por los Institutos de Puericultura.

b) Localización de las Gotas de Leche. La apertura de estos centros parecería estar ligada a la influencia de instituciones médicas y benéficas previamente existentes. De este modo, la Gota de Leche sería una suerte de continuidad respecto a hospitales, laboratorios, asilos o Casas de Caridad activas en una localidad. Las ciudades de mayor tamaño contaban con una ventaja al respecto. La relevancia de estos factores institucionales sanitarios locales contrastaría con lo que parece ser el escaso peso de las condiciones objetivas de mortalidad infantil. No fueron siempre las localidades con las menores expectativas de sobrevivencia entre los recién nacidos, aquellas que primero impulsaban la apertura de una Gotas de Leche. Más bien, parecen ser las que pudieron construir una percepción social de las consecuencias de la alta mortalidad experimentada, las que con mayor determinación actuaron para mitigarlos.

c) Iniciativa y toma de decisiones sobre la apertura de los centros. La implantación de una Gota de Leche en una localidad distó de ser fruto de acuerdos fáciles de alcanzar y de ejecución ágil. En algunas ocasiones se produjeron dilaciones notables, cuando no simplemente, la propuesta inicial no se ejecutó. Excepcionalmente, una vez abierta la Gota de Leche, en algunas pocas localidades acabó por cerrarse unos años después. Tampoco la gestión estuvo exenta de dificultades. Imposibles de tratar de forma exhaustiva en estas páginas, la mera inspección de las noticias periodísticas y de otras fuentes ha dejado entrever tensiones entre grupos locales o con las autoridades gubernativas, con probables conexiones con las circunstancias políticas del momento. Las dificultades en la financiación o, paradójicamente, las consecuencias de una mayor demanda de los servicios de la Gota de Leche fueron fuentes relevantes de tales tensiones.

Estos tres conjuntos de resultados describen el funcionamiento de una institución que encajaría en las características de la organización de la sanidad pública en España en el primer tercio del siglo XX (Rodríguez Ocaña y Martínez Navarro, 2010, pp. 52-80). En primer lugar, por el peso de las condiciones locales tanto en lo relativo a los factores de localización como al proceso de toma de decisiones y de organización de las Gotas de Leche. En segundo, por la relevancia de la interacción entre los intereses corporativos médicos y las organizaciones caritativas o filantrópicas, además de la propia administración sanitaria. Con una posición dominante derivada de su función en la "construcción de los riesgos» (Nathanson, 1996, pp. 614-615), las relaciones entre la profesión médica y determinadas elites locales habría resultado decisiva en la apertura de algunas Gotas de Leche, como se ha visto, con independencia de los niveles vigentes de mortalidad. En tercero y último, la débil iniciativa pública, especialmente de la administración, en la promoción y organización de estos establecimientos. No sólo los problemas de una limitada financiación de la sanidad pública, sino de la organización burocrática (Molero Mesa y Jiménez Wana, 2000) habrían dejado a la administración a remolque de los acontecimientos. La mención de la creación de las Gotas de Leche como secciones de los Institutos de 
Puericultura, promovida por el Reglamento de Sanidad Provincial de 1925 y otras normativas de organización municipal y provincial, sería el ejemplo de cómo se acababa institucionalizando lo que las iniciativas locales hacía tiempo venían realizando.

Los resultados hasta aquí reseñados deben entenderse como primeras evidencias de las posibilidades que ofrecen unas fuentes documentales como las empleadas en este trabajo. Un estudio más intenso de las mismas y el complemento de otro tipo de registros y documentación histórica permitirían calibrar el papel desempeñado por las Gotas de Leche en la mejora de la salud infantil en la España contemporánea.

\section{NOTAS}

1. Las delegaciones españolas de los tres congresos, Paris (1905), Bruselas (1907) y Berlín (1911) las formaron 28, 7 y 15 miembros, respectivamente. Esto suponía, en el congreso de París ser la mayor delegación de diecinueve, después de la del país anfitrión. En Bruselas, la quinta de veintiséis y en Berlín, la octava de treinta y cuatro. Cifras obtenidas a partir de los datos publicados por C. Rollet (Rollet, 2001,p.116).

2. Así contamos con investigaciones monográficas sobre Gotas de Leche en localidades como Madrid (Majan, 1990), Alicante (Perdiguero Gil y Bernabeu Mestre, 1999, 2005) Gijón (Chamizo, 1999,García 2003), Reus (Arnavat et alt, 1995), Menorca (Motilla y Sureda 2008), Huelva (Segovia Azcárate, 1995; Aguilera y Rodríguez, 2008) y Logroño (Cerrillo, Iruzubieta y Fandiño, 2008).

3. Entre el personal sanitario que participó en las Gotas de Leche e Institutos de Puericultura habría las enfermeras, aunque con una institucionalización más tardía que la de los médicos, llegaron a incorporarse a la atención maternoinfantil antes de la Guerra Civil (véase Bernabeu y Gascón, 1999.p.61-66). Una primera evaluación del impacto de las Gotas de Leche sobre el descenso de la mortalidad infantil urbana en Muñoz Pradas (2012).

4. Algunos autores han clasificado tal consultorio como Gota de Leche (Orzola 1995, p.99; Labay Matias 2012, p.11). Pero lo propios contemporáneos no llegaron a considerarla como tal (Puig y Mayol, 1904).

5. Entendidas como fuentes producidas y publicadas por la administración. Datos estadísticos también manejados por otros autores contemporáneos, suelen coincidir con aquellas fuentes, por ejemplo, Sandino Agudo (1925) en la Conferencia Nacional de Seguros celebrada en Barcelona en 1922.

6. Por ejemplo, en el "Boletín Provincial de la Provincia de Orense", el 6 de Diciembre de 1906 p. 3. Donde la Inspección General de Sanidad Exterior pide a los Ayuntamientos remitir datos sobre "Instituciones benéficas de carácter oficial para la infancia", citándose entre estas a las Gotas de Leche.

\section{AGRADECIMIENTOS}

Esta investigación ha recibido apoyo financiero del Ministerio de Economía y Competitividad a través del proyecto HAR2013-47182-C02-01 y de la Generalitat de Catalunya a través de 2014SGR591. Se reconoce la asistencia de Guillermo Villacampa, como becario de colaboración, en diferentes fases de esta investigación. Joaquín Muñoz Gispert contribuyó desinteresadamente a la traducción del alemán del texto de la comunicación del Dr.Rafael Ulecia al congreso de Berlín de 1911. Se agradecen las observaciones realizadas por los evaluadores para la mejora del texto. Como es habitual, el autor es el responsable último de la presente versión.

7. Solamente es la existencia de una Gota de Leche en León la única discrepancia entre el listado de "Los Nuevos apuntes...", en el que consta, y el elaborado por el Dr.Ulecia para el congreso de Berlín, en el que no es citada.

8. http://prensahistorica.mcu.es/es/estaticos/contenido. cmd?pagina=estaticos/presentacion

9. http://www.archivodemurcia.es/pandora.aspx?nmenu=4\&sub=3

10. De forma complementaria también se emplean los estudios y monografías publicados sobre Gotas de Leche citados en la nota al pie número 2 .

11. Esta circunstancia sería, por ejemplo, la de aquellas Gotas de Leche situadas en Institutos de Puericultura y de las que no se da cuenta en la noticia.

12. Durante la fase de recopilación de información se han reunido noticias de Gotas de Leche en localidades para las que no se ha encontrado referencia alguna en las bases digitales de prensa. Este sería el caso de Sòller, Jijona o Segorbe.

13. Estas comprenden a las mencionadas de Ávila, Lugo, Pontevedra, Soria, Teruel y Gerona, la de Sta. Cruz de Tenerife que cerró a los pocos meses de abrirse en 1907. La cifra inicial de 86 quedará, por tanto, reducida a 79 localidades.

14. Una implantación sanitaria bajo control militar y con un papel activo de organizaciones internacionales como la Cruz Roja véanse los estudios de Martínez Antonio (2013, 2014).

15. Esta cifra no computaría lo que serían locales o dispensarios abiertos por una misma institución. La información al respecto en la prensa histórica no suele ser siempre precisa. Obviamente de tenerse en cuenta este aspecto la cifra sería mayor, próxima al centenar. Las situaciones más conocidas serían las de las ciudades de Madrid y Barcelona, recuérdese que por ejemplo, en la primera el Instituto Municipal de Puericultura llegó a abrir hasta ocho dispensarios y en la segunda, la asociación "Lucha contra la mortalidad infantil" inauguró hasta tres dispensarios antes de 1936. 
16. En concreto, se trata de 17 localidades para las que este tipo de evidencia ha sido publicada en la prensa o reseñada en las monografías: Albacete, Barcelona, Bilbao, Cáceres, Ceuta, Cuenca, La Coruña, Huesca, Madrid, Mahón, Salamanca, Santander, Sevilla, Toledo, Vitoria, Zamora y Zaragoza.

17. No se incluye a la ciudad de Sta. Cruz de Tenerife que, de acuerdo a lo que se explica más adelante, abrió una Gota de Leche en 1907 pero la tendría cerrada en 1910.

18. Circunstancia que también recogió la prensa local. Por ejemplo, en "La Prensa: diario republicano" de la ciudad de Sta. Cruz de Tenerife el 11 de Agosto de 1926 se describen las tres secciones que deberán albergar, según la legislación aprobada, los Institutos de Maternología y Puericultura: “a) Comedor de embarazadas y de madres lactantes. b) Gota de Leche. c) Casa-cuna".

19. Véase también referencias a las mismas en el caso de la Gota de Leche de Alicante, "la pugna soterrada entre el Instituto de Higiene y Laboratorio Municipal y el Decano del Cuerpo de Beneficencia Municipal" (Perdiguero y Bernabeu, 1999, p. 298) y la de Reus, con las críticas de las aso-

\section{BIBLIOGRAFÍA}

Aguilera Hernández, María Isabel y Rodríguez Pérez, Margarita (2008), "La Gota de Leche onubense: La asistencia y el control del niños sano en la primera mitad del siglo XX", Híades. Revista de Historia de la Enfermería, 10, pp. 465-475.

Anaut Bravo, Sagrario (1999), "Acercamiento a las economías familiares de Pamplona en el primer tercio del siglo XX", Vasconia: Cuadernos de historia-geografía, 28, pp. 29-44.

Apple, Rima D. (1987), Mothers and Medicine; A social history of infant feeding 1890-1950. Madison, The University of Wisconsin Press.

Arbelo, Antonio (1962), La Mortalidad de la Infancia en España 1901-1950. Madrid, Consejo Superior de Investigaciones Científicas, pp. 321-324.

Arnavat, Albert; Pagès, Montserrat y Amorós, Xavier (1995), L'Institut de Puericultura Dr. Frias. "La Gota de LLet" Reus 1919-1994. Reus, Ajuntament.

Ayuntamiento de Barcelona (1913), Anuario Estadístico de la Ciudad de Barcelona. Barcelona,Heinrich y Cia.

Barona, Josep Lluís (2007), “¿Por qué mueren los niños? El debate ideológico sobre la salud infantil en la sociedad española (1904-1939)". En: Campos, Ricardo; Montiel, Luis y Huertas Rafael. (Coords.), Medicina, Ideología e Historia en España (siglos XVI-XXI). Madrid, Consejo Superior de Investigaciones Científicas, pp. 287-299.

Bernabeu Mestre, Josep y Gascón Pérez, Encarna (1999), Historia de la Enfermería de Salud Pública en España (18601977). Murcia, Publicaciones de la Universidad de Alicante.

Cerrillo Rubio, María.I; Iruzubieta Barragán, Fco. Javier y Fandiño Pérez, Roberto G. (2008), Un Siglo de la Gota de Leche. Arquitectura, Sanidad y Juventud. Logroño, Gobierno de la Rioja, Instituto de Estudios Riojanos. ciaciones católicas a la iniciativa de la Asociación Reusenca de Caridad de patrocinar la Gota de Leche por "no hacer ostentación del espíritu cristiano" (Arnavat et alt. 1995, p.23).

20. La información reproducida en esta Tabla procede de los estudios monográficos publicados para Alicante, Madrid, Mahón y Reus (ver nota 2), en esta última, la cifra de ingresos es la recogida en la revista "Puericultura" de 19201923, publicación del mismo Instituto de Puericultura. La correspondiente a Barcelona, de las noticias publicadas en "La Vanguardia", "Anuario Estadístico de la Ciudad de Barcelona" años 1913 a 1918. La de Zamora, de la prensa local , el "Heraldo de Zamora" entre 1916 y 1921, consultada en la BVPH.

21. Estimación propia a partir de los datos publicados por Perdiguero y Bernabeu ( 1999, p.302).

22. Aunque probablemente esta cifra subestima la que investigaciones futuras podrían revisar al alza, de no suponer las mismas una variación extremadamente elevada respecto a la establecida en este trabajo, continuarían suponiendo magnitudes inferiores a los 5 centros por cada diez mil nacidos.

Chamizo, Carmen (1999), La Gota de Leche y la Escuela de Enfermeras. Gijón, Gráficas Covadonga.

Cunningham, Hugh (2005), Children and Childhood in Western Society Since 1500. Second Edition. Harlow, Pearson.

De Arana Amurrio, José Ignacio y Zafra Anta, Miguel Angel (2014), "Transformación de la lactancia y consiguiente desaparición de las Gotas de Leche", Historia y significación de las Gotas de Leche en España, Cuadernos de Historia de la Pediatría Española, 8, Octubre, pp. 33-38.

Dupâquier, Jacques y Dupâquier, Michel (1985), Histoire de la Démographie. Paris, Librairie Académique Perrin.

Fernández Teijeiro, Juan José (2014), “El Dr. Pereda Elordi y la Gota de Leche de Santander: una memoria y un olvido", Historia y significación de las Gotas de Leche en España, Cuadernos de Historia de la Pediatría Española, 8, Octubre, pp. 28-32.

Fernández Menéndez, José Manuel, (2014), “El infatigable luchador Dr. Avelino González y sus Gotas de Leche de Gijón", Historia y significación de las Gotas de Leche en España, Cuadernos de Historia de la Pediatría Española, 8, Octubre, pp. 23-27.

García Galán, Sonia (2011), “De las prácticas tradicionales a la supervisión médica en el ejercicio de la maternidad Asturias 1900-1931", Dynamis, 31 (1), pp. 131-157.

García García, Eduardo (2003), La Gota de Leche. Casa Cuna de Gijón. Gijón, Ayuntamiento de Gijón.

Gondra Rezola, Juan (2003), "La sanidad municipal en Bilbao hasta su encrucijada durante los años de la 'Transición'”, Gaceta Médica de Bilbao, Suplemento, 100 (1), pp. 36-39.

Isern de Huguenin, Carmen (1945), Lucha contra la mortalidad infantil de Barcelona. Memoria de sus actividades con mo- 
tivo de su XXV Aniversario. Barcelona, Casa Provincial de Caridad.

Junta Administradora de la Gota de Leche de San Sebastián (1953), La Gota de Leche de San Sebastián en sus primeros cincuenta años 1903-1954. San Sebastián, Caja de Ahorros Provincial de Guipúzcoa.

Labay Matias, Miguel (2012), "Paediatrics, the People and Politicians in Spain - History, Development, Reality and Future". En: Öner Özdemir (ed.), Contemporary Pediatrics, In Tech Publisher, pp. 3-24. [en línea], disponible en: http:// www.intechopen.com/articles/show/title/pediatrics-thepeople-and-politicians-in-spain-history-developmentreality-and-future, [consultado el 07/07/2014].

Loste, L. (1933), "El Instituto Nipiológico de Huesca”, La Medicina de los Niños, Enero, pp. 4-10.

Luna Rodrigo, Gloria (1984), “La Población Urbana en España 1869-1930", Boletín de la Asociación de Demografía Histórica, VI (1), pp. 25-68.

Maján Gil, Natividad (1990), La Protección a la Infancia en España a través de la Obra de Rafael Ulecia y Cardona y de los Consultorios de Niños y Gotas de Leche. Universidad Complutense de Madrid.

Marland, Hilary (1992), "The medicalization of motherhood: doctors and infant welfare in the Netherlands, 1901-1930". En: Fildes, Valerie; Marks, Lara y Marland, Hilary (eds.) Women and Children First. International Maternal and Infant Welfare 1870-1945. London, Routledge, pp. 74-96.

Martínez Antonio, Francisco Javier (2013), "En la Enfermedad y en la Salud: medicina y sanidad españolas en Marruecos (1906-1956)". En: Aragón Reyes, Manuel (dir.), El Protectorado Español en Marruecos: La Historia Trascendida. Bilbao, Ed. Iberdrola, pp. 363-392.

Martínez Antonio, Francisco Javier (2014), "Resilient Modernisation: Morocco's agency in Red Cross projects from Hassan I to the Rif Republic, 1886-1926", Asclepio, 66 (1), pp. 0-32.

McCleary, G.F. (1904), "The Infants' milk depot: its history and function", Journal of Hygiene, IV (3), July, pp. 329-368.

Ministerio de Gobernación (1908), Leyes y disposiciones vigentes de protección a la infancia. Madrid, Imprenta del Asilo de Huérfanos.

Ministerio de Gobernación (1912-15-18), Nuevos apuntes para el estudio y la organización en España de las instituciones de beneficencia y de previsión. Madrid, Est. Tip. Suc. Rivadeneyra.

Molero Mesa, Jorge y Jiménez Wana, Isabel (2000), "Salud y burocracia en España. Los Cuerpos de Sanidad Nacional (1855-1951)", Revista Española de Sanidad Pública, 74 monográfico, pp. 45-79.

Moreno Martínez, Pedro Luis (1999), "La Protección a la Infancia en Cartagena (1908-1936): instituciones e iniciativas", Historia de la Educación Revista Interuniversitaria, 18, pp. 127-147.
Motilla Xavier y Sureda Bernat (2008), La gota de LLet. Protecció a la Infancia i Educació social a la Menorca contemporània. Menorca, Institut Menorquí d’Estudis.

Muñoz Machado Santiago (1975), La Sanidad Pública en España (Evolución histórica y situación actual). Madrid, Instituto de Estudios Administrativos.

Muñoz Pradas, Francisco (2012), "Las Gotas de Leche y el descenso de la mortalidad infantil urbana en España (19001936)", Revista de Demografía Histórica, XXX, pp. 127-164.

Nathanson, Constance A. (1996), "Disease Prevention as Social Change: Toward a Theory of Public Health", Population and Development Review, 22 (4), pp. 609-637.

Orzola i Lecha, Emili (1995), Evolució de la Pediatría catalana al segle XIX, Tesis Doctoral. Universidad de Barcelona

Perdiguero Gil, Enrique (1997), "Problemas de salud e higiene en el ámbito local". En: Bernabeu Mestre, Josep; Esplugues i Pellicer, Josep Xavier y Robles González, Elena (eds.), Higiene $i$ salubritat en els municipis valencians (1813-1939). Alicante, Seminari Estudis sobre la Ciència, pp. 17-41.

Perdiguero-Gil, Enrique y Bernabeu Mestre, Josep (1999), "La Gota de Leche de Alicante (1925-1940)". En: Benito Llloris Àngel; Blay Meseguer, Francesc Xavier y Lloret Pastor, Joan (eds.), Beneficència i Sanitat en els municipis valencians. Alcoi Seminari d'Estudis sobre Ciència, Associació Cultural Alcoià-Comtat, Centre Alcoià d'Estudis Històrics i Arqueològics, pp. 291-310.

Perdiguero-Gil Enrique y Bernabeu Mestre Josep (2005), “Child Care in Urban and Rural Alicante: the Gota de Leche". En: Barona Josep Lluis and Cherry Steven (eds.), Health and Medicine in Rural Europe (1850-1945). Valencia, Seminari d'Estudis sobre la Ciència, pp. 347-359.

Porter, Dorothy (1999), Health, Civilization and the State. London, Routledge.

Puig Solé, M. y Mayol Mir, A. (1904), "Servicio lácteo infantil de Barcelona”, La medicina de los Niños, 5, pp. 208-212.

Rodríguez Ocaña, Esteban y Garcia-Duarte Ros, Olga (1984), "Rafael Garcia-Duarte Salcedo (1894-1936). Supuestos cientifico-sociales de un médico puericultor en la Segunda República española", Dynamis, 4, pp. 175-197.

Rodríguez Ocaña E; Ortiz Gómez T. y García Duarte Ros, O. (1985a), "Los consultorios de lactantes y gotas de leche en España”, Jano, XXIX, pp. 1066-72.

Rodríguez Ocaña, Esteban (1985b), "Aspectos sociales de la Pediatría Española anteriores a la Guerra Civil (1936-39)". En: Peset, J.L. (ed.), La Ciencia Moderna y el Nuevo Mundo. Madrid, Consejo Superior de Investigaciones Científicas, pp. 443-460.

Rodríguez Ocaña, Esteban (1996), “Una medicina para la infancia”. En: Borras LLop, José María (dir.), Historia de la infancia en la España contemporánea 1834-1936. Madrid, Ministerio de Trabajo y Asuntos Sociales, Fundación Germán Sánchez Rupérez, pp. 149-169. 
Rodríguez Ocaña, Esteban (1999), "La construcción de la salud infantil. Ciencia, medicina y educación en la transición sanitaria en España", Historia Contemporánea, 18, pp. 19-52.

Rodríguez Ocaña, Esteban y Martínez Navarro Ferrán (2010), Salud Pública en España: de la Edad Media al Siglo XXI. Sevilla, Escuela Andaluza de Salud Pública.

Rollet, Catherine (1990), La Politique à l'egard de la petite enfance sous la Ille République. Paris, PUF.

Rollet, Catherine (2001), "La santé et la protection de l'enfant vues à travers les congrès internationaux (1880-1920)", Annales de Démographie Historique, 1, pp. 97-116.

Samper Villagrasa, Maria Pilar (2004), "Semblanza de un pediatra ilustre: don Andrés Martínez Vargas", Argensola: Revista de Ciencias Sociales del Instituto de Estudios Altoaragoneses, 114, pp. 345-370.

Sandino Agudo, Enrique (1925), "La Beneficencia pública en España. Breves notas y cuadros estadísticos". En: Conferencia Nacional de Seguros de Enfermedad, Invalidez y Maternidad. Barcelona, Noviembre 1922. Madrid, Imp. Sobrinos Sucesora M.Minuesa de los Rios, pp. 129-141.

Santos Valera, Susana (2003), "La Gota de Leche en la ciudad de León: una institución benéfica municipal", Argutorio: Revista de la Asociación Cultural "Monte Irago", 4 (10), pp. 27-28.
Segovia Azcárate, José María (1995), Gota de Leche. Instituto Municipal de Puericultura de Huelva. Huelva, Imprenta Jiménez.

Ulecia y Cardona, Rafael (1906), "La Gota de Leche de Madrid y la propagación de esta institución en España", Revista de Medicina y Cirugía Práctica, 72-73, pp. 205-213.

Ulecia y Cardona, Rafael (1912), “Consultation für Brustkinder und Gouttes de Lait". En : Keller,A. y Kumbler Ch.J. (dirs.), Säuglinnsfürsorge und Kinderschutz in den europäischen Staaten, Vol 1. Berlin, Springer, pp. 838-841.

Urkia Etxabe, José Maria (1999), Cien años de Medicina en Gipuzkoa 1899-1999. Donostia-San Sebastián, Fundacion Kutxa.

Vega Gil, Leoncio; Hernández Díaz, José María; Cerezo Manrique, Juan Francisco y Martín Fraile, Bienvenido (1998), "Protección de la infancia y educación en Castilla y León (1900-1930)", Aula, 10, pp. 221-252.

Vögele, Jörg y Woelk, Wolfang (2002), "Public health and the development of infant mortality in Germany, 1875-1930", The History of the Family, 7 (4), pp. 585-599.

Wickes, I.G (1953), "A History of Infant Feeding. Part V", Archives of Disease in Childhood, 28 (142), pp. 495-502. 
ANEXO 1. Listado de Gotas de Leche en España según año de inauguración (1903-1934)

\begin{tabular}{|c|c|c|c|c|c|}
\hline $\begin{array}{c}\text { Año } \\
\text { Inauguración }\end{array}$ & Localidad & $\begin{array}{l}\text { num. } \\
\text { localidad }\end{array}$ & $\begin{array}{l}\text { Capitales } \\
\text { Provincia }\end{array}$ & Referencia & Observación \\
\hline 1890 & Barcelona & & $x$ & “Nuevos apuntes......” & $\begin{array}{l}\text { Hospital Niños Pobres fundado por Francisco Vidal } \\
\text { Solares. }\end{array}$ \\
\hline 1903 & Barcelona & 1 & $x$ & Rodíguez Ocaña (1996) & $\begin{array}{l}\text { Casa Municipal Lactancia se abre en calle Sepúlveda } \\
\text { en } 1903 \text { y traslada a calle Valdonzella en } 1904 .\end{array}$ \\
\hline 1903 & $\begin{array}{c}\text { San } \\
\text { Sebastián }\end{array}$ & 2 & $x$ & $\begin{array}{l}\text { “Nuevos apuntes.....”)/Maján } \\
\text { (1990) /Urkia (1999) }\end{array}$ & $\begin{array}{l}\text { Primera obra social conjunta de las Cajas de Ahorro } \\
\text { Provincial y Municipal. }\end{array}$ \\
\hline 1903 & Bilbao & 3 & $x$ & $\begin{array}{l}\text { “Nuevos apuntes...")/Ulecia } \\
\text { (1912)/"Heraldo Alavés" } 31 \\
\text { Diciembre } 1903\end{array}$ & $\begin{array}{l}\text { En el Hospital Inocentes, también Gota de Leche en } \\
\text { Ayuntamiento según Ulecia y prensa de la época. }\end{array}$ \\
\hline 1904 & Logroño & 4 & $x$ & "Nuevos apuntes......" & \\
\hline 1904 & Madrid & 5 & $x$ & "Nuevos apuntes......" & $\begin{array}{l}\text { Dirección del Doctor Rafael Ulecia.Patrocinada por } \\
\text { los marqueses de Casa-Torre. }\end{array}$ \\
\hline 1905 & Santander & 6 & $x$ & Fernández Teijeiro (2014) & $\begin{array}{l}\text { Por iniciativa del Dr Pablo Pereda Elordi. Inaugurada } \\
\text { en el entresuelo de la Casa de la Caridad. }\end{array}$ \\
\hline 1905 & Zaragoza & 7 & $x$ & Ulecia (1912) & $\begin{array}{l}\text { Fundada } 9 \text { de Marzo por iniciativa de los } \\
\text { farmacéuticos Tomás Bayod y Miguel Bel. }\end{array}$ \\
\hline 1906 & Vitoria & 8 & $x$ & $\begin{array}{l}\text { El Heraldo Alavés } 17 \text { Abril } \\
1906\end{array}$ & \\
\hline 1906 & $\begin{array}{l}\text { Talavera } \\
\text { de la } \\
\text { Reina }\end{array}$ & 9 & & $\begin{array}{l}\text { "Nuevos apuntes......" / "El } \\
\text { Bien Público" } 16 \text { Junio } 1906\end{array}$ & Inaugura el Alcalde (Médico). \\
\hline 1906 & Mahón & 10 & & $\begin{array}{l}\text { Motilla y Sureda (2008) / } \\
\text { "Nuevos apuntes......" }\end{array}$ & $\begin{array}{l}\text { Iniciativa del Dr. E Alabern y entidades culturales } \\
\text { locales. }\end{array}$ \\
\hline 1906 & Jaca & 11 & & "Nuevos apuntes......" & \\
\hline 1906 & Madrid & & $x$ & "Nuevos apuntes......" & $\begin{array}{l}\text { Instalada en la Inclusa. Sufraga los gatos la Duquesa } \\
\text { de Castrejón. }\end{array}$ \\
\hline 1906 & Sevilla & 12 & $\mathrm{x}$ & $\begin{array}{l}\text { "Nuevos apuntes......" / } \\
\text { Sandino Agudo (1925) }\end{array}$ & Dirigida por el Dr. Ciriaco Esteban. \\
\hline 1906 & Málaga & 13 & $x$ & "ABC" 15 Noviembre 1906 & \\
\hline 1907 & $\begin{array}{l}\text { Palma } \\
\text { Mallorca }\end{array}$ & 14 & $x$ & $\begin{array}{l}\text { “Nuevos apuntes..."/ } \\
\text { "La Tarde: diario } \\
\text { independiente...." } 4 \text { Enero } \\
1907\end{array}$ & \\
\hline 1907 & Santander & & $\mathrm{x}$ & $\begin{array}{l}\text { Fernández Teijeiro (2014)/ } \\
\text { Ulecia (1912) }\end{array}$ & $\begin{array}{l}\text { Presentacion Gota de Leche iniciativa Institución } \\
\text { Reina Victoria, sostenida por industriales locales. }\end{array}$ \\
\hline 1907 & $\begin{array}{l}\text { Sta Cruz } \\
\text { Tenerife }\end{array}$ & 15 & $\mathrm{x}$ & Ulecia (1912) & $\begin{array}{l}\text { Noticia existencia Consultorio con Gota de Leche. No } \\
\text { parece continuar activo en } 1911 .\end{array}$ \\
\hline 1907 & Zaragoza & & $x$ & “Nuevos apuntes......" & \\
\hline 1907 & Bilbao & & $x$ & $\begin{array}{l}\text { Gondra Rezola (2003)/ Ulecia } \\
\text { (1912) }\end{array}$ & $\begin{array}{l}1906 \text { probable año fundación y } 1907 \text { inaugurada. } \\
\text { Según Ulecia (1912) funciona mejor que la primitiva. }\end{array}$ \\
\hline 1908 & Madrid & & $x$ & $\begin{array}{l}\text { “Nuevos apuntes......” / } \\
\text { Rodríguez Ocaña et alt } \\
\text { (1985a) }\end{array}$ & $\begin{array}{l}\text { Integrada con otras consultas infantiles en el } \\
\text { Instituto de Puericultura de Madrid en } 1913 .\end{array}$ \\
\hline 1908 & Salamanca & 16 & $\mathrm{x}$ & $\begin{array}{l}\text { "Nuevos apuntes......" } \\
\text { /"Revista Médica } \\
\text { Salmantina" Diciembre } 1908\end{array}$ & $\begin{array}{l}\text { Inaugurada el } 11 \text { de Octubre, sostenida por el } \\
\text { Ayuntamiento. }\end{array}$ \\
\hline 1909 & Cartagena & 17 & & $\begin{array}{l}\text { “Nuevos apuntes......"/ } \\
\text { Moreno Martinez (1999) }\end{array}$ & $\begin{array}{l}\text { En la Casa de Expósitos. Impulsada creación por } \\
\text { Junta Local Protección Infancia. Refundada en } 1921 .\end{array}$ \\
\hline
\end{tabular}




\begin{tabular}{|c|c|c|c|c|c|}
\hline $\begin{array}{l}\text { Año } \\
\text { Inauguración }\end{array}$ & Localidad & $\begin{array}{l}\text { num. } \\
\text { localidad }\end{array}$ & $\begin{array}{l}\text { Capitales } \\
\text { Provincia }\end{array}$ & Referencia & Observación \\
\hline 1909 & Burgos & 18 & $x$ & $\begin{array}{l}\text { “Nuevos apuntes......" /"El } \\
\text { Papa Moscas" } 16 \text { Agosto } \\
1909\end{array}$ & $\begin{array}{l}\text { Iniciativa particular de la Asociación Burgalesa de } \\
\text { Beneficencia y Cultura. }\end{array}$ \\
\hline 1910 & Utrera & 19 & & “Nuevos apuntes......" & \\
\hline 1910 & Valencia & 20 & $x$ & $\begin{array}{l}\text { "Nuevos apuntes......" / } \\
\text { Maján (1990) }\end{array}$ & $\begin{array}{l}\text { Existe un Consultorio de Niños de Pecho en Valencia } \\
\text { en } 1904 \text { (Maján, 1990). }\end{array}$ \\
\hline 1910 & Arjona & 21 & & $\begin{array}{l}\text { "Nuevos apuntes......" } \\
\text { /"ABC" } 24 \text { Enero } 1910\end{array}$ & $\begin{array}{l}\text { Inaugurada Enero, por iniciativa de Francisco Serrano } \\
\text { Navarro, propietario con ayuda de tres médicos. }\end{array}$ \\
\hline 1910 & Valladolid & 22 & $x$ & “Nuevos apuntes......" & $\begin{array}{l}\text { Inaugurada a fines de } 1910 . \text { Inicia actividad el } 1 \text { Enero } \\
\text { 1911. Vega Gil et alt (1998) dan la fecha de } 1906 .\end{array}$ \\
\hline 1911 & Guadalajara & 23 & $x$ & $\begin{array}{l}\text { Maján (1990)/"Flores y } \\
\text { Abejas" } 1911\end{array}$ & Impulsada por el Dr E. Ballesteros. \\
\hline 1912 & Orense & 24 & $x$ & $\begin{array}{l}\text { "Nuevos apuntes......" / "La } \\
\text { Vanguardia" } 10 \text { Abril } 1912\end{array}$ & $\begin{array}{l}\text { Dirigen los doctores Lino Porto Porto y José Eire } \\
\text { Santalla. }\end{array}$ \\
\hline 1912 & La Coruña & 25 & $x$ & $\begin{array}{l}\text { "La Vanguardia" } 17 \text { Mayo } \\
1912\end{array}$ & \\
\hline 1913 & Oviedo & 26 & $\mathrm{x}$ & García Galán (2011) & $\begin{array}{l}\text { Iniciativa de la maestra Asunción Izquierdo, apoyada } \\
\text { por el doctor Arturo Buylla. }\end{array}$ \\
\hline 1913 & Segovia & 27 & $x$ & $\begin{array}{l}\text { C. Alvaro "La gota de leche" } \\
\text { en "Norte de Castilla" } 10 \\
\text { Noviembre } 2010 .\end{array}$ & $\begin{array}{l}\text { Fundada por el Dr. Leopoldo Moreno, instalada en } \\
\text { una casa de su propiedad. }\end{array}$ \\
\hline 1913 & Murcia & 28 & $x$ & $\begin{array}{l}\text { “El Tiempo" } 7 \text { Abril 1913/"La } \\
\text { Vanguardia" } 13 \text { Diciembre } \\
1913\end{array}$ & $\begin{array}{l}\text { Iniciativa de Lorenzo Pausa (Director Escuela Normal } \\
\text { de Maestros), fundada por él y una Junta de Damas. }\end{array}$ \\
\hline 1913 & Madrid & & & $\begin{array}{l}\text { Rodríguez Ocaña et alt } \\
\text { (1985a) }\end{array}$ & Creación del Instituto Municipal de Puericultura. \\
\hline 1913 & Barcelona & & $x$ & $\begin{array}{l}\text { "Anuario Estadístico Ciudad } \\
\text { de Barcelona" } 1914\end{array}$ & $\begin{array}{l}\text { Nuevo edificio de la Casa Municipal de Maternidad y } \\
\text { Lactancia en la Gran Via de Les Corts Catalanes. }\end{array}$ \\
\hline 1914 & Huesca & 29 & $\mathrm{x}$ & Loste (1933) & $\begin{array}{l}\text { Por iniciativa del Dr. Bercial la Junta de Protección a } \\
\text { la Infancia funda Gota de Leche. }\end{array}$ \\
\hline 1915 & Vigo & 30 & & $\begin{array}{l}\text { "La Vanguardia" } 30 \text { Agosto } \\
1915\end{array}$ & \\
\hline 1915 & Toledo & 31 & $x$ & $\begin{array}{l}\text { “Diario Toledano" y el “Eco } \\
\text { Toledano" año } 1915\end{array}$ & $\begin{array}{l}\text { Probable año inauguracion dadas las noticias de } \\
\text { actividad y de dirección médica en esa fecha. }\end{array}$ \\
\hline 1915 & Granada & 32 & $\mathrm{x}$ & $\begin{array}{l}\text { Rodríguez Ocaña y Garcia } \\
\text { Duarte Ros (1984) }\end{array}$ & $\begin{array}{l}\text { Impulsada Dr Rafael Garcia Duarte, profesor } \\
\text { Universidad de Granada. }\end{array}$ \\
\hline 1916 & Zamora & 33 & $\mathrm{x}$ & $\begin{array}{l}\text { "Heraldo de Zamora" } 26 \\
\text { Junio } 1916\end{array}$ & \\
\hline 1916 & Cádiz & 34 & $x$ & $\begin{array}{l}\text { "La Correspondencia" } 10 \\
\text { Enero } 1916\end{array}$ & \\
\hline 1916 & Pamplona & 35 & $x$ & $\begin{array}{l}\text { Anaut (1998) /Anuario } \\
\text { Estadístico España (1916- } \\
\text { 1923) }\end{array}$ & \\
\hline 1916 & Cáceres & 36 & $x$ & “La Montaña” 16 Junio 1925 & $\begin{array}{l}\text { Con motivo inauguración de } 1925 \text { se menciona que } \\
\text { en ese año se inició actividad de la Gota de Leche. }\end{array}$ \\
\hline 1917 & Melilla & 37 & & "ABC" 15 Setiembre 1917 & \\
\hline 1918 & Lérida & 38 & $x$ & $\begin{array}{l}\text { "La Vanguardia" } 31 \\
\text { Diciembre } 1918\end{array}$ & \\
\hline 1918 & El Ferrol & 39 & & "El Orzan” 30 Octubre 1918 & $\begin{array}{l}\text { En 1927, se reorganiza su funcionamiento(“El Orzán” } \\
21 \text { Julio 1927). }\end{array}$ \\
\hline
\end{tabular}




\begin{tabular}{|c|c|c|c|c|c|}
\hline $\begin{array}{l}\text { Año } \\
\text { Inauguración }\end{array}$ & Localidad & $\begin{array}{l}\text { num. } \\
\text { localidad }\end{array}$ & $\begin{array}{l}\text { Capitales } \\
\text { Provincia }\end{array}$ & Referencia & Observación \\
\hline 1918 & Palencia & 40 & $x$ & $\begin{array}{l}\text { "La Correspondencia" } 21 \\
\text { Julio } 1918\end{array}$ & \\
\hline 1918 & Tarragona & 41 & $x$ & “La Cruz” 20 Junio 1918 & \\
\hline 1919 & Córdoba & 42 & $x$ & $\begin{array}{l}\text { "Diario de Córdoba" } 30 \text { Abril } \\
1919\end{array}$ & \\
\hline 1919 & Reus & 43 & & Arnavat et alt (1995) & $\begin{array}{l}\text { Promotores Dr A.Frias y la Asociación Reusenca de } \\
\text { Caridad. }\end{array}$ \\
\hline 1919 & Cuenca & 44 & $x$ & $\begin{array}{l}\text { "Boletín Estadística } \\
\text { Municipal" } 1 \text { Octubre } 1919\end{array}$ & \\
\hline 1920 & Albacete & 45 & $x$ & $\begin{array}{l}\text { "La Vanguardia" } 22 \\
\text { Septiembre } 1920\end{array}$ & \\
\hline 1922 & $\begin{array}{l}\text { Ciudad } \\
\text { Real }\end{array}$ & 46 & $x$ & $\begin{array}{l}\text { Maján (1990)/ “El Pueblo } \\
\text { Manchego" } 7 \text { Julio } 1922\end{array}$ & $\begin{array}{l}\text { Noticia inicio obras del edificio en 1921, de actividad } \\
\text { desde } 1922 .\end{array}$ \\
\hline 1921 & Cartagena & & & Moreno Martinez (1999) & $\begin{array}{l}\text { Nueva Gota de Leche. Cerrada la ubicada en la Casa } \\
\text { de Expósitos.Traslado en } 1929 \text { a la Casa del Niño. }\end{array}$ \\
\hline 1921 & Tanger & 47 & & $\begin{array}{l}\text { "La Correspondencia" } 8 \\
\text { Enero 1921/ Martinez } \\
\text { Antonio ( 2013 ) }\end{array}$ & \\
\hline 1922 & Larache & 48 & & $\begin{array}{l}\text { "La Correspondencia de } \\
\text { España" } 8 \text { Diciembre } 1922\end{array}$ & \\
\hline 1923 & Santander & & $\mathrm{x}$ & $\begin{array}{l}\text { "La Vanguardia" } 9 \text { Marzo } \\
1923\end{array}$ & $\begin{array}{l}\text { Entrega del edificio de la Gota de Leche, sufragado } \\
\text { por santanderinos en Cuba. }\end{array}$ \\
\hline 1923 & Ceuta & 49 & & $\begin{array}{l}\text { "La Correspondencia" } 10 \\
\text { Julio } 1923\end{array}$ & Se establece en el Hospital de la Cruz Roja. \\
\hline 1923 & Barbastro & 50 & & $\begin{array}{l}\text { "Medicina de los Niños", } \\
\text { 1924, Septiembre, no } 297 .\end{array}$ & $\begin{array}{l}\text { Fundada bajo impulso del Dr. Martínez Vargas y } \\
\text { denominado "Instituto Nipiológico". }\end{array}$ \\
\hline 1924 & Huelva & 51 & $x$ & $\begin{array}{l}\text { Aguilera y Rodríguez (2008)/ } \\
\text { "ABC". Ed.Andalucía. } 13 \\
\text { Febrero } 1931\end{array}$ & \\
\hline 1924 & Barcelona & & & $\begin{array}{l}\text { "La Vanguardia" } 30 \\
\text { Diciembre } 1924\end{array}$ & $\begin{array}{l}\text { Reapertura nueva Gota de Leche en el Hospital de } \\
\text { Niños Pobres. }\end{array}$ \\
\hline 1925 & Alicante & 52 & $x$ & $\begin{array}{l}\text { Perdiguero Gil y Bernabeu } \\
\text { Mestre }(1999,2005)\end{array}$ & \\
\hline 1925 & Cáceres & & $x$ & “La Montaña” 16 Junio 1925 & $\begin{array}{l}\text { Inauguración bajo el auspicio de la Iglesia, Acción } \\
\text { Social Católica. }\end{array}$ \\
\hline 1925 & Badajoz & 53 & $x$ & $\begin{array}{l}\text { “Correo de la Mañana” } 2 \\
\text { Diciembre } 1925\end{array}$ & $\begin{array}{l}\text { Noticia edificio instalado y equipado, falta un } \\
\text { permiso para inicio actividad. El Gobernador } \\
\text { respalda apertura. }\end{array}$ \\
\hline 1925 & Gijón & 54 & & $\begin{array}{l}\text { Garcia Garcia (2003)/ } \\
\text { Chamizo (1999) }\end{array}$ & $\begin{array}{l}\text { Iniciativa del Dr Avelino González, con apoyo de la } \\
\text { Junta Municipal de Protección a la Infancia. }\end{array}$ \\
\hline 1926 & Mérida & 55 & & $\begin{array}{l}\text { "La Libertad" } 7 \text { Enero } \\
\text { 1926/"Correo de la Mañana" } \\
18 \text { Junio } 1926\end{array}$ & Inauguración en el Hospital Municipal. \\
\hline 1927 & $\begin{array}{l}\text { Castellón } \\
\text { de la } \\
\text { Plana }\end{array}$ & 56 & $x$ & $\begin{array}{l}\text { "La Vanguardia" } 8 \text { Diciembre } \\
1927\end{array}$ & \\
\hline 1927 & La Coruña & & $x$ & $\begin{array}{l}\text { "La Libertad" } 20 \text { Diciembre } \\
1927\end{array}$ & $\begin{array}{l}\text { Inauguración de la nueva Casa de la Maternidad } \\
\text { y Gota de Leche, en terreno cedido por el } \\
\text { Ayuntamiento. }\end{array}$ \\
\hline 1927 & Vitoria & & $\mathrm{x}$ & $\begin{array}{l}\text { "La Vanguardia” } 25 \\
\text { Diciembre } 1927\end{array}$ & Inauguración de nuevos locales de la Gota de Leche. \\
\hline
\end{tabular}




\begin{tabular}{|c|c|c|c|c|c|}
\hline $\begin{array}{l}\text { Año } \\
\text { Inauguración }\end{array}$ & Localidad & $\begin{array}{l}\text { num. } \\
\text { localidad }\end{array}$ & $\begin{array}{l}\text { Capitales } \\
\text { Provincia }\end{array}$ & Referencia & Observación \\
\hline 1927 & Sabadell & 57 & & $\begin{array}{l}\text { "La Vanguardia" } 11 \text { Junio } \\
1927\end{array}$ & $\begin{array}{l}\text { Inauguración del Instituto de Puericultura y } \\
\text { Maternología. Funda la Junta Local de protección a } \\
\text { la infancia. }\end{array}$ \\
\hline 1927 & $\begin{array}{c}\text { Don } \\
\text { Benito }\end{array}$ & 58 & & $\begin{array}{l}\text { "Correo Extremeño" } 3 \\
\text { Agosto } 1929\end{array}$ & $\begin{array}{l}\text { Noticia de la existencia aquel año del } \\
\text { establecimiento en un discurso del alcalde el año } \\
1929 .\end{array}$ \\
\hline 1928 & Ceuta & & & $\begin{array}{l}\text { "La Vanguardia” } 21 \text { Marzo } \\
\text { 1928/ "ABC" } 21 \text { Marzo } 1928\end{array}$ & $\begin{array}{l}\text { Establecida por la Junta Municipal de Protección de } \\
\text { la Infancia. }\end{array}$ \\
\hline 1928 & Toledo & & $\mathrm{x}$ & "La Libertad" 10 Enero 1928 & $\begin{array}{l}\text { Fundada por Junta de Proteccion de la Infancia y } \\
\text { la Cruz Roja. Sería un segundo local o un nuevo } \\
\text { edificio. }\end{array}$ \\
\hline 1929 & Elda & 59 & & $\begin{array}{l}\text { "La Prensa" } 15 \text { Dicembre } \\
1929\end{array}$ & $\begin{array}{l}\text { Anuncio de la inauguración por el Ministro de } \\
\text { Gobernación, General Martínez Anido. }\end{array}$ \\
\hline 1929 & Cuenca & & $\mathrm{x}$ & $\begin{array}{l}\text { "La Voz de Cuenca" } 11 \\
\text { Febrero } 1929\end{array}$ & Inauguración de un nuevo edificio. \\
\hline 1930 & Tortosa & 60 & & $\begin{array}{l}\text { "La Vanguardia” } 18 \text { Junio } \\
1930\end{array}$ & En un local de la Cruz Roja. \\
\hline 1930 & Alicante & & & $\begin{array}{l}\text { Perdiguero Gil y Bernabeu } \\
\text { Mestre (1999) (2005) }\end{array}$ & Traslado del servicio a un nuevo edificio. \\
\hline 1930 & Huesca & & & Loste (1933) & $\begin{array}{l}\text { Nueva instalación del Consultorio y Gota de Leche. } \\
\text { Se agrupan bajo el nombre de Instituto Nipiológico. }\end{array}$ \\
\hline 1931 & $\begin{array}{l}\text { Becerril } \\
\text { de } \\
\text { Campos }\end{array}$ & 61 & & $\begin{array}{l}\text { “El Dia de Palencia” } 22 \text { Junio } \\
1931\end{array}$ & $\begin{array}{l}\text { Visita a la instalación próxima a inaugurarse, } \\
\text { localizada en la sede de la Cruz Roja. }\end{array}$ \\
\hline 1932 & Guadarrama & 62 & & $\begin{array}{l}\text { “Heraldo de Toledo" } 8 \text { Enero } \\
1932\end{array}$ & $\begin{array}{l}\text { Construcción en una institución de prevencion de la } \\
\text { tuberculosis infantil. }\end{array}$ \\
\hline 1934 & León & 63 & $\mathrm{x}$ & $\begin{array}{l}\text { "La Vanguardia" } 15 \text { Abril } \\
\text { 1934/ Santos Valera (2003) }\end{array}$ & \\
\hline
\end{tabular}


ANEXO 2. Listado de localidades con Gotas de Leche en España por orden alfabético (1890-934)

\begin{tabular}{|c|c|c|c|c|c|c|c|}
\hline n & Localidad & $\begin{array}{l}\text { Año } \\
\text { Inaugura }\end{array}$ & $\begin{array}{l}\text { Año } \\
\text { Actividad }\end{array}$ & Provincia & $\begin{array}{l}\text { Región } \\
\text { Histórica }\end{array}$ & Referencia/Fuente & Observación \\
\hline \multirow[t]{2}{*}{1} & Albacete & & 1916 & Albacete & Murcia & $\begin{array}{l}\text { "Anuario Estadístico España"( } \\
\text { 1916-1923) }\end{array}$ & $\begin{array}{l}\text { Referencia a litros de leche distribuidos en } \\
\text { la capital en los Anuarios Estadísticos de } \\
\text { España 1916-23. }\end{array}$ \\
\hline & Albacete & 1920 & 1920 & Albacete & Murcia & $\begin{array}{l}\text { "La Vanguardia" } 22 \text { Septiembre } \\
1920\end{array}$ & Primera piedra del edificio de la Gota Leche. \\
\hline 2 & Algeciras & & 1923 & Cádiz & Andalucia & $\begin{array}{l}\text { "La Correspondencia" } 9 \text { Marzo } \\
1923\end{array}$ & $\begin{array}{l}\text { Visita a la Gota de Leche de la Reina Victoria. } \\
\text { Un artículo publicado en } 1911 \text { ya solicitaba } \\
\text { la institución. }\end{array}$ \\
\hline \multirow[t]{5}{*}{3} & Alicante & & 1914 & Alicante & Valencia & $\begin{array}{l}\text { "Diario de Alicante" } 7 \text { Mayo } \\
1914\end{array}$ & $\begin{array}{l}\text { Petición de datos sobre funcionamiento } \\
\text { Gota de Leche de la Coruña para instalar una } \\
\text { en Alicante. }\end{array}$ \\
\hline & Alicante & & 1917 & Alicante & Valencia & $\begin{array}{l}\text { "La Correspondencia de } \\
\text { España" } 28 \text { Septiembre } 1917\end{array}$ & $\begin{array}{l}\text { Visita del Gobernador civil a la Gota de Leche } \\
\text { de Madrid. Interesado en implantarla en la } \\
\text { localidad. }\end{array}$ \\
\hline & Alicante & & 1923 & Alicante & Valencia & "El Luchador" 2 Octubre 1925 & $\begin{array}{l}\text { Acuerdo del Ayuntamiento para crear Gota } \\
\text { de Leche. }\end{array}$ \\
\hline & Alicante & 1925 & & Alicante & Valencia & $\begin{array}{l}\text { Perdiguero Gil y Bernabeu } \\
\text { Mestre (1999) (2005) }\end{array}$ & Inauguracion Gota Leche. \\
\hline & Alicante & 1930 & & Alicante & Valencia & $\begin{array}{l}\text { Perdiguero Gil y Bernabeu } \\
\text { Mestre (1999) (2005) }\end{array}$ & $\begin{array}{l}\text { Traslado del servicio a un nuevo edificio en } \\
\text { Octubre. }\end{array}$ \\
\hline 4 & Almeria & & 1929 & Almeria & Andalucia & $\begin{array}{l}\text { “ABC" Edicion Andalucía } 10 \\
\text { Noviembre } 1929\end{array}$ & $\begin{array}{l}\text { Distribución de dinero entre instituciones } \\
\text { de beneficencia en la ciudad que incluye a la } \\
\text { Gota de Leche. }\end{array}$ \\
\hline 5 & Andujar & & 1931 & Jaén & Andalucia & $\begin{array}{l}\text { “ABC" Edición Andalucía } 25 \\
\text { Junio } 1931\end{array}$ & $\begin{array}{l}\text { Según carta remitida por asociaciones } \\
\text { femeninas católicas e instituciones como la } \\
\text { Gota de Leche. }\end{array}$ \\
\hline 6 & Arjona & 1910 & & Jaén & Andalucia & $\begin{array}{l}\text { "Nuevos apuntes......" /"ABC" } 24 \\
\text { Enero } 1910\end{array}$ & $\begin{array}{l}\text { Inaugurada por iniciativa de Francisco } \\
\text { Serrano Navarro, propietario, con ayuda de } \\
\text { tres médicos. }\end{array}$ \\
\hline \multirow[t]{2}{*}{7} & Badajoz & & 1906 & Badajoz & Extremadura & $\begin{array}{l}\text { “La Región Extremeña” } 5 \text { Julio } \\
1906\end{array}$ & $\begin{array}{l}\text { Aprobada moción en el Ayuntamiento para } \\
\text { instalar Gota de Leche y consultorio de niños } \\
\text { de pecho. }\end{array}$ \\
\hline & Badajoz & 1925 & & Badajoz & Extremadura & $\begin{array}{l}\text { "Correo de la Mañana" } 2 \\
\text { Diciembre } 1925\end{array}$ & $\begin{array}{l}\text { Edificio instalado y equipado, falta un } \\
\text { permiso para el inicio de la actividad. }\end{array}$ \\
\hline 8 & Baena & & 1932 & Córdoba & Andalucia & $\begin{array}{l}\text { "Boletín Oficial del Colegio de } \\
\text { Médicos" } 15 \text { Noviembre } 1932\end{array}$ & $\begin{array}{l}\text { Anuncio para proveer la plaza de director del } \\
\text { "Dispensario Municipal Gota de Leche". }\end{array}$ \\
\hline 9 & Barbastro & 1923 & & Huesca & Aragón & $\begin{array}{l}\text { “Medicina de los Niños", 1924, } \\
\text { Septiembre, no } 297 .\end{array}$ & $\begin{array}{l}\text { Fundada bajo el impulso del Dr. Martínez } \\
\text { Vargas y denominado "Instituto Nipiológico". }\end{array}$ \\
\hline \multirow[t]{5}{*}{10} & Barcelona & 1890 & & Barcelona & Cataluña & $\begin{array}{l}\text { Nuevos apuntes...... Ministerio } \\
\text { Gobernación (1912-1915-18 }\end{array}$ & $\begin{array}{l}\text { Hospital Niños Pobres Fundada por Francisco } \\
\text { Vidal Solares. }\end{array}$ \\
\hline & Barcelona & 1903 & & Barcelona & Cataluña & Rodíguez Ocaña (1999) & $\begin{array}{l}\text { Casa Municipal Lactancia se abre en calle } \\
\text { Sepúlveda em } 1903 \text { y traslada a calle } \\
\text { Valdonzella en } 1904 .\end{array}$ \\
\hline & Barcelona & 1913 & & Barcelona & Cataluña & $\begin{array}{l}\text { "Anuario Estadístico Ciudad de } \\
\text { Barcelona" } 1914\end{array}$ & $\begin{array}{l}\text { Nuevo edificio de la Casa Municipal de } \\
\text { Maternidad y Lactancia en Gran Via de Les } \\
\text { Corts Catalanes. }\end{array}$ \\
\hline & Barcelona & 1920 & & Barcelona & Cataluña & Isern de Huguenin (1945) & $\begin{array}{l}\text { Inicio actividades de la "Lucha contra la } \\
\text { Mortalidad Infantil". Incluye servicios de } \\
\text { Gota de Leche. }\end{array}$ \\
\hline & Barcelona & 1924 & & Barcelona & Cataluña & $\begin{array}{l}\text { "La Vanguardia" } 30 \text { Diciembre } \\
1924\end{array}$ & $\begin{array}{l}\text { Reapertura Gota de Leche en Hospital Niños } \\
\text { Pobres. }\end{array}$ \\
\hline 11 & $\begin{array}{l}\text { Becerril de } \\
\text { Campos }\end{array}$ & 1931 & & Palencia & C.Vieja & $\begin{array}{l}\text { "El Dia de Palencia" } 22 \text { Junio } \\
1931\end{array}$ & $\begin{array}{l}\text { Visita a la instalación próxima a inaugurarse, } \\
\text { localizada en la sede de la Cruz Roja. }\end{array}$ \\
\hline 12 & Bejar & & 1911 & Salamanca & León & $\begin{array}{l}\text { "La Victoria Semanario de } \\
\text { Bejar" } 7 \text { Enero } 1911\end{array}$ & $\begin{array}{l}\text { Referencia a actividades benéficas, mención } \\
\text { Gota de Leche atiende a } 15 \text { niños.. }\end{array}$ \\
\hline 13 & Bilbao & & 1903 & Vizcaya & P. Vasco & “Nuevos apuntes......" & $\begin{array}{l}\text { Ese año se implanta en la Inclusa una estufa } \\
\text { esterilizadora de la leche. }\end{array}$ \\
\hline
\end{tabular}




\begin{tabular}{|c|c|c|c|c|c|c|c|}
\hline $\mathrm{n}$ & Localidad & $\begin{array}{c}\text { Año } \\
\text { Inaugura }\end{array}$ & $\begin{array}{l}\text { Año } \\
\text { Actividad }\end{array}$ & Provincia & $\begin{array}{l}\text { Región } \\
\text { Histórica }\end{array}$ & Referencia/Fuente & Observación \\
\hline & Bilbao & 1906 & & Vizcaya & P. Vasco & $\begin{array}{l}\text { Gondra Rezola (2003) / } \\
\text { Maján(1990) }\end{array}$ & $\begin{array}{l}\text { Año de la fundación. El Ayuntamiento } \\
\text { aprueba un dictamen a favor de este centro } \\
\text { el } 19 \text { Octubre. }\end{array}$ \\
\hline & Bilbao & 1907 & & Vizcaya & P. Vasco & $\begin{array}{l}\text { "El Eco de Navarra" } 22 \text { Agosto } \\
\text { 1907/ "Heraldo Alavés" } 15 \\
\text { Marzo 1907/Ulecia (1912) }\end{array}$ & $\begin{array}{l}\text { Inauguración según "El Eco de Navarra” y } \\
\text { Ulecia (1912).En “Heraldo Alavés" traslado a } \\
\text { un nuevo local. }\end{array}$ \\
\hline 14 & Burgos & 1909 & & Burgos & C. Vieja & $\begin{array}{l}\text { "El Papa-Moscas" } 12 \\
\text { Septiembre } 1909\end{array}$ & $\begin{array}{l}\text { Inauguración Gota de Leche. Iniciativa } \\
\text { Asociación Burgalesa de Beneficencia y } \\
\text { cultura. }\end{array}$ \\
\hline \multirow[t]{4}{*}{15} & Cáceres & 1916 & & Cáceres & Extremadura & “La Montaña” 16 Junio 1925 & $\begin{array}{l}\text { Con motivo inauguración de } 1925 \text { se } \\
\text { menciona que en ese año se inició actividad } \\
\text { de la Gota de Leche. }\end{array}$ \\
\hline & Cáceres & & 1920 & Cáceres & Extremadura & $\begin{array}{l}\text { "Anuario Estadístico de } \\
\text { España"(1916-1923) }\end{array}$ & $\begin{array}{l}\text { En Anuario consta reparto de leche en Gota } \\
\text { de Leche del año } 1920 \text { hasta } 1923 .\end{array}$ \\
\hline & Cáceres & & 1921 & Cáceres & Extremadura & Sandino Agudo (1925) & Subvención a la Gota de Leche. \\
\hline & Caceres & 1925 & & Cáceres & Extremadura & “La Montaña” 16 Junio 1925 & $\begin{array}{l}\text { Inauguración bajo el auspicio de la Iglesia, } \\
\text { Acción Social Católica. Probablemente nuevo } \\
\text { edificio. }\end{array}$ \\
\hline \multirow[t]{3}{*}{16} & Cádiz & 1916 & & Cádiz & Andalucia & $\begin{array}{l}\text { "La Correspondencia" } 10 \text { Enero } \\
1916\end{array}$ & $\begin{array}{l}\text { Inauguración de la Gota de Leche instituida } \\
\text { por el Gobernador Civil }\end{array}$ \\
\hline & Cadiz & & 1916 & Cadiz & Andalucia & "La Vanguardia" 14 Agosto 1916 & $\begin{array}{l}\text { Alcalde de Córdoba la visita con el propósito } \\
\text { de conocer funcionamiento para instalar una } \\
\text { en esa ciudad. }\end{array}$ \\
\hline & Cádiz & & 1916 & Cádiz & Andalucia & $\begin{array}{l}\text { "Anuario Estadístico de España" } \\
(1916-1923)\end{array}$ & $\begin{array}{l}\text { Referencia a litros de leche distribuidos en la } \\
\text { capital en los Anuarios desde } 1916 \text { a } 1923 .\end{array}$ \\
\hline \multirow[t]{2}{*}{17} & Cartagena & 1909 & & Murcia & Murcia & $\begin{array}{l}\text { “Nuevos apuntes......” / Moreno } \\
\text { Martínez (1999) }\end{array}$ & $\begin{array}{l}\text { En la Casa de Expósitos. Impulsada por } \\
\text { la Junta Local Protección Infancia. Será } \\
\text { refundada en } 1921 .\end{array}$ \\
\hline & Cartagena & 1921 & & Murcia & Murcia & Moreno Martinez (1999) & $\begin{array}{l}\text { Nueva Gota de Leche.Trasladada el año } 1929 \\
\text { a la Casa del Niño. }\end{array}$ \\
\hline 18 & $\begin{array}{l}\text { Castellón } \\
\text { Plana }\end{array}$ & 1927 & & Castellón & Valencia & $\begin{array}{l}\text { "La Vanguardia" } 8 \text { Diciembre } \\
1927\end{array}$ & Inauguración Gota de Leche. \\
\hline \multirow[t]{2}{*}{19} & Ceuta & 1923 & & Ceuta & Norte Africa & $\begin{array}{l}\text { "La Correspondencia" } 10 \text { Julio } \\
1923\end{array}$ & $\begin{array}{l}\text { Establece la Gota de Leche en el Hospital de } \\
\text { la Cruz Roja. }\end{array}$ \\
\hline & Ceuta & 1928 & & Ceuta & Norte Africa & $\begin{array}{l}\text { "La Vanguardia" } 21 \text { Marzo } \\
\text { 1928/ "ABC" } 21 \text { Marzo } 1928\end{array}$ & $\begin{array}{l}\text { Establecida por la Junta Municipal de } \\
\text { Protección de la Infancia. }\end{array}$ \\
\hline 20 & $\begin{array}{l}\text { Ciudad } \\
\text { Rodrigo }\end{array}$ & 1917 & & Salamanca & León & $\begin{array}{l}\text { "Avante.Semanario } \\
\text { Mirobrigense" } 17 \text { Febrero } 1917\end{array}$ & $\begin{array}{l}\text { Inauguración Gota de Leche por iniciativa } \\
\text { Municipal. }\end{array}$ \\
\hline \multirow[t]{2}{*}{21} & $\begin{array}{l}\text { Ciudad } \\
\text { Real }\end{array}$ & & 1916 & Ciudad Real & C. Nueva & $\begin{array}{l}\text { “Anuario Estadístico de España" } \\
\text { (1916-1923) }\end{array}$ & $\begin{array}{l}\text { En Anuario consta reparto de leche en Gota } \\
\text { de Leche el año } 1916 \text { y siguientes, hasta } \\
1923 .\end{array}$ \\
\hline & $\begin{array}{l}\text { Ciudad } \\
\text { Real }\end{array}$ & 1922 & & Ciudad Real & C.Nueva & $\begin{array}{l}\text { "El Pueblo Manchego" } \\
11 \text { Enero1921/"El Pueblo } \\
\text { Manchego" } 7 \text { Julio } 1922\end{array}$ & $\begin{array}{l}\text { Noticia inicio obras del edificio en 1921, de } \\
\text { actividad desde } 1922 .\end{array}$ \\
\hline \multirow[t]{3}{*}{22} & Córdoba & 1919 & & Córdoba & Andalucia & $\begin{array}{l}\text { "Diario de Córdoba" } 30 \text { Abril } \\
1919\end{array}$ & \\
\hline & Córdoba & & 1919 & Córdoba & Andalucia & $\begin{array}{l}\text { "Anuario Estadístico de España" } \\
(1916-1923)\end{array}$ & $\begin{array}{l}\text { Referencia a litros de leche distribuidos en la } \\
\text { capital en los Anuarios desde } 1919 \text { a } 1923 .\end{array}$ \\
\hline & Córdoba & & 1921 & Córdoba & Andalucia & Sandino Agudo (1925) & Subvención a la Gota de Leche. \\
\hline \multirow[t]{3}{*}{23} & La Coruña & & 1911 & Coruña & Galicia & $\begin{array}{l}\text { "La Vanguardia" } 30 \text { Octubre } \\
1911\end{array}$ & Proyecto de Gota de Leche para la ciudad. \\
\hline & La Coruña & 1912 & & Coruña & Galicia & $\begin{array}{l}\text { "Nuevos apuntes......" /"La } \\
\text { Vanguardia" } 17 \text { Mayo } 1912\end{array}$ & $\begin{array}{l}\text { Inauguración con presencia del Gobernador } \\
\text { Civil según La Vanguardia. }\end{array}$ \\
\hline & La Coruña & 1927 & & Coruña & Galicia & $\begin{array}{l}\text { "La Libertad" } 20 \text { Diciembre } \\
1927\end{array}$ & $\begin{array}{l}\text { Inauguración de la nueva Casa de la } \\
\text { Maternidad y Gota de Leche, en terreno } \\
\text { cedido por el Ayuntamiento. }\end{array}$ \\
\hline 24 & Cuenca & 1919 & & Cuenca & C.Nueva & $\begin{array}{l}\text { "Boletín de Estadística } \\
\text { Municipal" } 1 \text { Octubre } 1919\end{array}$ & Inicio del servicio el primero de Septiembre. \\
\hline
\end{tabular}




\begin{tabular}{|c|c|c|c|c|c|c|c|}
\hline n & Localidad & $\begin{array}{c}\text { Año } \\
\text { Inaugura }\end{array}$ & $\begin{array}{c}\text { Año } \\
\text { Actividad }\end{array}$ & Provincia & $\begin{array}{l}\text { Región } \\
\text { Histórica }\end{array}$ & Referencia/Fuente & Observación \\
\hline & Cuenca & & 1919 & Cuenca & C.Nueva & $\begin{array}{l}\text { “Anuario Estadístico de España" } \\
(1916-1923)\end{array}$ & $\begin{array}{l}\text { Referencia a litros de leche distribuidos en la } \\
\text { capital en los Anuarios años } 1919 \text { y } 1920 .\end{array}$ \\
\hline & Cuenca & 1929 & & Cuenca & C.Nueva & $\begin{array}{l}\text { "La Voz de Cuenca" } 11 \text { Febrero } \\
1929\end{array}$ & Inauguración de un nuevo edificio. \\
\hline 25 & $\begin{array}{c}\text { Don } \\
\text { Benito } \\
\end{array}$ & 1927 & & Badajoz & Extremadura & $\begin{array}{l}\text { “Correo Extremeño" } 3 \text { Agosto } \\
1929\end{array}$ & $\begin{array}{l}\text { Noticia de la existencia de una Gota de Leche } \\
\text { ese año en un discurso del alcalde en } 1929 .\end{array}$ \\
\hline 26 & Elda & 1929 & & Alicante & Valencia & “La Prensa” 15 Diciembre 1929 & $\begin{array}{l}\text { Anuncio de la inauguración por el Ministro } \\
\text { de Gobernación, General Martínez Anido. }\end{array}$ \\
\hline 27 & Ferrol & 1918 & & Coruña & Galicia & $\begin{array}{l}\text { "El Orzan" } 30 \text { Octubre 1918/ "La } \\
\text { Vanguardia" } 23 \text { Octubre 1921 }\end{array}$ & $\begin{array}{l}\text { En 1927, se reorganiza su funcionamiento("El } \\
\text { Orzán" } 21 \text { Julio 1927). }\end{array}$ \\
\hline 28 & Figueres & & 1933 & Gerona & Cataluña & "La Vanguardia" 3 Marzo 1933 & $\begin{array}{l}\text { Preparación de un acto benéfico para la Gota } \\
\text { de Leche. }\end{array}$ \\
\hline 29 & Gerona & & 1910 & Gerona & Cataluña & $\begin{array}{l}\text { "Heraldo de Gerona" } 1 \\
\text { Diciembre } 1910\end{array}$ & $\begin{array}{l}\text { Propuesta de instalar una Gota de Leche en } \\
\text { la ciudad. }\end{array}$ \\
\hline 30 & Gijón & 1925 & & Asturias & Asturias & $\begin{array}{l}\text { Garcia Garcia (2003), Chamizo } \\
\text { (1999) }\end{array}$ & $\begin{array}{l}\text { Iniciativa del Dr Avelino González, con apoyo } \\
\text { de la Junta Municipal de Protección a la } \\
\text { Infancia. }\end{array}$ \\
\hline 31 & Granada & 1915 & & Granada & Andalucia & $\begin{array}{l}\text { Rodríguez Ocaña y Garcia } \\
\text { Duarte Ros (1984) }\end{array}$ & $\begin{array}{l}\text { Impulsada Dr Rafael Garcia Duarte } \\
\text { (Catedrático Universidad de Granada). }\end{array}$ \\
\hline & Granada & & 1916 & Granada & Andalucia & $\begin{array}{l}\text { "Anuario Estadístico de España" } \\
\text { (1916-1923) }\end{array}$ & $\begin{array}{l}\text { Referencia a litros de leche distribuidos en la } \\
\text { capital en los Anuarios desde } 1916 \text { a } 1923 .\end{array}$ \\
\hline 32 & Guadalajara & 1911 & & Guadalajara & C.Nueva & $\begin{array}{l}\text { Maján (1990)/"Flores y Abejas" } \\
1911\end{array}$ & Impulsada por el Dr E. Ballesteros. \\
\hline 33 & Guadarrama & & 1932 & Madrid & C.Nueva & $\begin{array}{l}\text { “Heraldo de Toledo" } 8 \text { Enero } \\
1932\end{array}$ & $\begin{array}{l}\text { Construcción en una institución de } \\
\text { prevencion de la tuberculosis infantil. }\end{array}$ \\
\hline \multirow[t]{2}{*}{34} & Huelva & & 1916 & Huelva & Andalucia & $\begin{array}{l}\text { "Anuario Estadístico de España" } \\
(1916-1923)\end{array}$ & $\begin{array}{l}\text { Referencia a litros de leche distribuidos en la } \\
\text { capital en los Anuarios desde } 1916 \text { a } 1923 .\end{array}$ \\
\hline & Huelva & 1924 & & Huelva & Andalucia & $\begin{array}{l}\text { Aguilera Hernández y Rodríguez } \\
\text { Pérez (2008) }\end{array}$ & \\
\hline \multirow[t]{3}{*}{35} & Huesca & 1914 & & Huesca & Aragón & Loste (1933) & $\begin{array}{l}4 \text { de Enero por iniciativa del Dr Bercial la } \\
\text { Junta de Protección a la Infancia funda la } \\
\text { Gota de Leche. }\end{array}$ \\
\hline & Huesca & & 1916 & Huesca & Aragón & $\begin{array}{l}\text { "Anuario Estadístico de } \\
\text { España"(1916-1923) }\end{array}$ & $\begin{array}{l}\text { Referencia a litros de leche distribuidos en la } \\
\text { capital en los Anuarios desde } 1916 \text { a } 1923 .\end{array}$ \\
\hline & Huesca & 1930 & & Huesca & Aragón & Loste Echeto (1933) & $\begin{array}{l}\text { Nueva instalación del Consultorio y Gota } \\
\text { de Leche. Se agrupan bajo el nombre de } \\
\text { Instituto Nipiológico. }\end{array}$ \\
\hline 36 & Jaca & 1906 & & Huesca & Aragón & "Nuevos apuntes......" & $\begin{array}{l}\text { El Inventario no hace constar más } \\
\text { información. }\end{array}$ \\
\hline \multirow[t]{3}{*}{37} & Jaén & & $\begin{array}{c}1912-15- \\
18\end{array}$ & Jaén & Andalucia & "Nuevos apuntes......" & $\begin{array}{l}\text { El inventario en una de sus tablas hace } \\
\text { constar } 2 \text { Gotas de Leche. }\end{array}$ \\
\hline & Jaén & & 1913 & Jaén & Andalucia & $\begin{array}{l}\text { "La Correspondencia" } 30 \\
\text { Octubre } 1913\end{array}$ & $\begin{array}{l}\text { Nueva instalación del Consultorio y Gota } \\
\text { de Leche. Se agrupan bajo el nombre de } \\
\text { Instituto Nipiológico. }\end{array}$ \\
\hline & Jaén & & 1916 & Jaén & Andalucia & $\begin{array}{l}\text { "Anuario Estadístico de España" } \\
\text { (1916-1923) }\end{array}$ & $\begin{array}{l}\text { Referencia a litros de leche distribuidos en la } \\
\text { capital en los Anuarios desde } 1916 \text { a } 1921 .\end{array}$ \\
\hline \multirow[t]{2}{*}{38} & $\begin{array}{l}\text { Jerez de la } \\
\text { Frontera }\end{array}$ & & 1924 & Cádiz & Andalucia & “ABC" 27 Mayo 1924 & $\begin{array}{l}\text { Festival benéfico-novillada- en beneficio de } \\
\text { la Gota de Leche. }\end{array}$ \\
\hline & $\begin{array}{l}\text { Jerez de la } \\
\text { Frontera }\end{array}$ & & 1933 & Cádiz & Andalucia & $\begin{array}{l}\text { “ABC".Edición Andalucía. } 31 \\
\text { Enero } 1933\end{array}$ & $\begin{array}{l}\text { Noticia del fallecimiento del conde de } \\
\text { Garvey "que sostenía la institución de la } \\
\text { Gota de Leche". }\end{array}$ \\
\hline 39 & Larache & 1922 & & & Norte Africa & $\begin{array}{l}\text { "La Correspondencia de } \\
\text { España" } 8 \text { Diciembre } 1922\end{array}$ & $\begin{array}{l}\text { Inauguración Gota de la Leche, donde se } \\
\text { informa que la Duquesa de la Victoria "la } \\
\text { costea". }\end{array}$ \\
\hline 40 & $\begin{array}{l}\text { Las } \\
\text { Palmas }\end{array}$ & & 1929 & Canarias & Canarias & "La Vanguardia" 23 Abril 1929 & $\begin{array}{l}\text { Adquisición de material para la Gota de } \\
\text { Leche. }\end{array}$ \\
\hline 41 & León & 1934 & & León & León & $\begin{array}{l}\text { "La Vanguardia" } 15 \text { Abril 1934/ } \\
\text { Santos Valera (2003) }\end{array}$ & $\begin{array}{l}\text { Nuevo edificio con fondos que proceden } \\
\text { del Ayuntamiento, Diputación y donaciones } \\
\text { privadas. }\end{array}$ \\
\hline
\end{tabular}




\begin{tabular}{|c|c|c|c|c|c|c|c|}
\hline n & Localidad & $\begin{array}{c}\text { Año } \\
\text { Inaugura }\end{array}$ & $\begin{array}{l}\text { Año } \\
\text { Actividad }\end{array}$ & Provincia & $\begin{array}{l}\text { Región } \\
\text { Histórica }\end{array}$ & Referencia/Fuente & Observación \\
\hline \multirow[t]{2}{*}{42} & Lérida & & 1916 & Lérida & Cataluña & $\begin{array}{l}\text { "La Vanguardia" } 11 \text { Octubre } \\
1916\end{array}$ & $\begin{array}{l}\text { Exposición pública de los planos de la Gota } \\
\text { de Leche. Concurso público bajo iniciativa } \\
\text { del Ayuntamiento. }\end{array}$ \\
\hline & Lérida & 1918 & & Lérida & Cataluña & $\begin{array}{l}\text { "La Vanguardia" } 31 \text { Diciembre } \\
1918\end{array}$ & Recepción definitiva del Edificio. \\
\hline 43 & Logroño & 1904 & & Logroño & C.Vieja & "Nuevos apuntes......" & $\begin{array}{l}\text { Premio de la Exposición Internacional de } \\
\text { Higiene de Roma en } 1912 \text { ("La Vanguardia" } 3 \\
\text { Diciembre 1912). }\end{array}$ \\
\hline \multirow[t]{5}{*}{44} & Madrid & 1904 & & Madrid & C.Nueva & $\begin{array}{l}\text { "Nuevos apuntes......" /Maján } \\
\text { (1990) }\end{array}$ & $\begin{array}{l}\text { Dirección del Doctor Rafael Ulecia. } \\
\text { Patrocinada por los marqueses de Casa- } \\
\text { Torre. }\end{array}$ \\
\hline & Madrid & 1906 & & Madrid & C.Nueva & “Nuevos apuntes......" & $\begin{array}{l}\text { Instalada en la Inclusa. Sufraga los gatos la } \\
\text { Duquesa de Castrejón. }\end{array}$ \\
\hline & Madrid & 1908 & & Madrid & C.Nueva & $\begin{array}{l}\text { "Nuevos apuntes......" / } \\
\text { Rodríguez Ocaña et alt (1985a) }\end{array}$ & $\begin{array}{l}\text { Integrada con otras consultas infantiles en el } \\
\text { Instituto de Puericultura de Madrid en } 1913 .\end{array}$ \\
\hline & Madrid & 1913 & & Madrid & C.Nueva & Rodríguez Ocaña et alt (1985a) & $\begin{array}{l}\text { Creación del Instituto Municipal de } \\
\text { Puericultura. }\end{array}$ \\
\hline & Madrid & & 1916 & Madrid & C.Nueva & $\begin{array}{l}\text { "Anuario Estadístico de } \\
\text { España"(1916-1923) }\end{array}$ & $\begin{array}{l}\text { Referencia a litros de leche distribuidos en la } \\
\text { capital en los Anuarios desde } 1916 \text { a } 1923 .\end{array}$ \\
\hline \multirow[t]{2}{*}{45} & Mahon & 1906 & & Baleares & Baleares & $\begin{array}{l}\text { Motilla y Sureda (2008) / } \\
\text { "Nuevos apuntes......" }\end{array}$ & $\begin{array}{l}\text { Bajo impulso del Dr. E Alabern e instituciones } \\
\text { culturales locales. }\end{array}$ \\
\hline & Mahón & & 1934 & Baleares & Baleares & $\begin{array}{l}\text { "La Voz de Menorca" } 15 \\
\text { Diciembre } 1934\end{array}$ & $\begin{array}{l}\text { Apertura del Dispensario Higiene Infantil, } \\
\text { incluye Gota de Leche, supervisa Inspeccion } \\
\text { Provincial Sanidad. }\end{array}$ \\
\hline \multirow[t]{2}{*}{46} & Málaga & 1906 & & Málaga & Andalucia & “ABC" 15 Noviembre 1906 & $\begin{array}{l}\text { Fundada por la Sociedad Protectora de los } \\
\text { Niños. }\end{array}$ \\
\hline & Málaga & & 1916 & Málaga & Andalucia & $\begin{array}{l}\text { "Anuario Estadístico de } \\
\text { España"(1916-1923) }\end{array}$ & $\begin{array}{l}\text { Referencia a litros de leche distribuidos en la } \\
\text { capital en los Anuarios desde } 1916 \text { a } 1920 .\end{array}$ \\
\hline 47 & Manresa & 1933 & & Barcelona & Cataluña & $\begin{array}{l}\text { "La Vanguardia" } 1 \text { Setiembre } \\
1933\end{array}$ & $\begin{array}{l}\text { Inauguración del Consultorio de } \\
\text { Puericultura. }\end{array}$ \\
\hline 48 & Mataró & & 1930 & Barcelona & Cataluña & “La Vanguardia” 27 Julio 1930 & $\begin{array}{l}\text { Proyecto de Gota Leche a instalar en el } \\
\text { inaugurado Casal d'Infants. }\end{array}$ \\
\hline 49 & Melilla & 1917 & & & Norte Africa & “ABC" 15 Setiembre 1917 & Entrega del edificio. \\
\hline 50 & Mérida & 1926 & & Badajoz & Extremadura & "La Libertad" 7 Enero 1926 & Inauguración en el Hospital Municipal. \\
\hline 51 & Miajadas & & 1927 & Cáceres & Extremadura & "Nuevo Día" 6 Agosto 1927 & $\begin{array}{l}\text { Actividades benéficas para pedir instalación } \\
\text { de Gota de Leche. }\end{array}$ \\
\hline 52 & Montoro & & 1920 & Córdoba & Andalucia & “La Voz" 10 Junio 1920 & $\begin{array}{l}\text { Información de que el Hospital municipal } \\
\text { cuenta con Gota de Leche. A cargo de una } \\
\text { Junta de Damas. }\end{array}$ \\
\hline \multirow[t]{3}{*}{53} & Murcia & 1913 & & Murcia & Murcia & $\begin{array}{l}\text { El Tiempo } 7 \text { Abril 1913/"La } \\
\text { Vanguardia" } 13 \text { Diciembre } 1913\end{array}$ & $\begin{array}{l}\text { Iniciativa de Lorenzo Pausa (Director Escuela } \\
\text { Normal de Maestros) y una Junta de Damas. }\end{array}$ \\
\hline & Murcia & & 1916 & Murcia & Murcia & $\begin{array}{l}\text { "Anuario Estadístico de España" } \\
\text { Años } 1916 \text { a } 1923\end{array}$ & $\begin{array}{l}\text { Referencia a litros de leche distribuidos en la } \\
\text { capital en los Anuarios desde } 1916 \text { a } 1923 .\end{array}$ \\
\hline & Murcia & & 1933 & Murcia & Murcia & “El Tiempo" 1 Agosto 1933 & $\begin{array}{l}\text { Gota de Leche se integra en el Instituto de } \\
\text { Puericultura y Maternología de la ciudad, } \\
\text { aprobado en } 1929 .\end{array}$ \\
\hline 54 & Olivares & & 1932 & Sevilla & Andalucia & $\begin{array}{l}\text { "ABC". Edición Andalucía } 10 \\
\text { Febrero } 1932\end{array}$ & $\begin{array}{l}\text { Donativos de un rico propietario a la Gota de } \\
\text { Leche de la localidad. }\end{array}$ \\
\hline 55 & Orense & 1912 & & Orense & Galicia & $\begin{array}{l}\text { "Nuevos apuntes......" / "La } \\
\text { Vanguardia" } 10 \text { Abril } 1912\end{array}$ & $\begin{array}{l}\text { Dirigen los doctores Lino Porto Porto y José } \\
\text { Eire Santalla. }\end{array}$ \\
\hline \multirow[t]{2}{*}{56} & Oviedo & 1913 & & Asturias & Asturias & Garcia Galán (2011) & $\begin{array}{l}\text { Iniciativa de la maestra Asunción Izquierdo, } \\
\text { apoyada por el doctor Arturo Buylla.. }\end{array}$ \\
\hline & Oviedo & & 1916 & Asturias & Asturias & $\begin{array}{l}\text { “Anuario Estadístico de España" } \\
(1916-1923)\end{array}$ & $\begin{array}{l}\text { Referencia a litros de leche distribuidos en la } \\
\text { capital en los Anuarios desde } 1916 \text { a } 1923 .\end{array}$ \\
\hline \multirow[t]{2}{*}{57} & Palencia & 1918 & & Palencia & C.Vieja & $\begin{array}{l}\text { "La Correspondencia" } 21 \text { Julio } \\
1918\end{array}$ & \\
\hline & Palencia & & 1919 & Palencia & C.Vieja & $\begin{array}{l}\text { "Anuario Estadístico de España" } \\
\text { (1916-1923) }\end{array}$ & $\begin{array}{l}\text { Referencia a litros de leche distribuidos en la } \\
\text { capital en los Anuarios desde } 1918 \text { a } 1923 .\end{array}$ \\
\hline
\end{tabular}




\begin{tabular}{|c|c|c|c|c|c|c|c|}
\hline n & Localidad & $\begin{array}{l}\text { Año } \\
\text { Inaugura }\end{array}$ & $\begin{array}{l}\text { Año } \\
\text { Actividad }\end{array}$ & Provincia & $\begin{array}{l}\text { Región } \\
\text { Histórica }\end{array}$ & Referencia/Fuente & Observación \\
\hline \multirow[t]{2}{*}{58} & $\begin{array}{l}\text { Palma } \\
\text { Mallorca }\end{array}$ & 1907 & & Baleares & Baleares & “Nuevos apuntes......" & \\
\hline & $\begin{array}{l}\text { Palma } \\
\text { Mallorca }\end{array}$ & & 1916 & Baleares & Baleares & $\begin{array}{l}\text { "Anuario Estadístico de España" } \\
(1916-1923)\end{array}$ & $\begin{array}{l}\text { Referencia a litros de leche distribuidos en la } \\
\text { capital en los Anuarios desde } 1916 \text { a } 1923 .\end{array}$ \\
\hline \multirow[t]{2}{*}{59} & Pamplona & 1916 & & Navarra & Navarra & $\begin{array}{l}\text { Anaut (1998) /"Anuario } \\
\text { Estadístico de España" (1916- } \\
\text { 1923) }\end{array}$ & $\begin{array}{l}\text { Inauguración de la Gota de Leche ligada a la } \\
\text { Inclusa. Cerrada en } 1935 .\end{array}$ \\
\hline & Pamplona & & 1916 & Navarra & Navarra & $\begin{array}{l}\text { "Anuario Estadístico de España" } \\
(1916-1923)\end{array}$ & $\begin{array}{l}\text { Referencia a litros de leche distribuidos en la } \\
\text { capital en los Anuarios desde } 1916 \text { a } 1923 .\end{array}$ \\
\hline 60 & $\begin{array}{l}\text { Puerto } \\
\text { Real }\end{array}$ & & 1930 & Cádiz & Andalucia & $\begin{array}{l}\text { “ABC".Edición Andalucía } 19 \\
\text { Octubre } 1930\end{array}$ & $\begin{array}{l}\text { Noticia de actividad benéfica para sostener } \\
\text { Gota de Leche de la localidad. }\end{array}$ \\
\hline 61 & Reus & 1919 & & Tarragona & Cataluña & Arnavat et alt (1995) & $\begin{array}{l}\text { Promotores Dr A.Frias y la Asociación } \\
\text { Reusenca de Caridad. }\end{array}$ \\
\hline 62 & Sabadell & 1927 & & Barcelona & Cataluña & “La Vanguardia” 11 Junio 1927 & $\begin{array}{l}\text { Inauguración del Instituto de Puericultura } \\
\text { y Maternología. Funda la Junta Local de } \\
\text { protección a la infancia. }\end{array}$ \\
\hline \multirow[t]{3}{*}{63} & Salamanca & 1908 & & Salamanca & León & “Nuevos apuntes......" & $\begin{array}{l}\text { Inaugurada el } 11 \text { de Octubre, sostenida por } \\
\text { el Ayuntamiento. }\end{array}$ \\
\hline & Salamanca & & 1916 & Salamanca & León & $\begin{array}{l}\text { "Anuario Estadístico de España" } \\
(1916-1923)\end{array}$ & $\begin{array}{l}\text { Referencia a litros de leche distribuidos en la } \\
\text { capital en los Anuarios desde } 1916 \text { a } 1923 .\end{array}$ \\
\hline & Salamanca & & 1918 & Salamanca & León & $\begin{array}{l}\text { "El Adelantado" } 18 \text { de Febrero } \\
\text { de } 1918\end{array}$ & Traslado de Gota de Leche a nuevos locales. \\
\hline \multirow[t]{2}{*}{64} & $\begin{array}{c}\text { San } \\
\text { Sebastián }\end{array}$ & 1903 & & Guipúzcoa & P.Vasco & $\begin{array}{l}\text { "Nuevos apuntes......" /Maján } \\
\text { (1990) /Urkia (1999) }\end{array}$ & $\begin{array}{l}\text { Primera obra social conjunta de las Cajas de } \\
\text { Ahorro Provincial y Municipal. }\end{array}$ \\
\hline & $\begin{array}{c}\text { San } \\
\text { Sebastián }\end{array}$ & & 1916 & Guipúzcoa & P.Vasco & $\begin{array}{l}\text { "Anuario Estadístico de España" } \\
\text { (1916-1923) }\end{array}$ & $\begin{array}{l}\text { Referencia a litros de leche distribuidos en la } \\
\text { capital en los Anuarios desde } 1916 \text { a } 1923 .\end{array}$ \\
\hline \multirow[t]{2}{*}{65} & $\begin{array}{l}\text { Sta Cruz } \\
\text { Tenerife }\end{array}$ & 1907 & & Canarias & Canarias & Ulecia (1912) & $\begin{array}{l}\text { Consultorio de Niños de Pecho con Gota de } \\
\text { leche. No activo cuando Ulecia presentó su } \\
\text { informe en } 1911\end{array}$ \\
\hline & $\begin{array}{l}\text { Sta Cruz } \\
\text { Tenerife }\end{array}$ & & 1917 & Canarias & Canarias & “La Prensa” 15 Mayo 1917 & $\begin{array}{l}\text { Referencia a un estudio para proponer } \\
\text { instalar una Gota de Leche en la ciudad. }\end{array}$ \\
\hline \multirow[t]{6}{*}{66} & Santander & 1905 & & Santander & C.Vieja & Fernandez Teijeiro (2014) & $\begin{array}{l}\text { Dr Pereda Elordi pone en marcha Gota de } \\
\text { Leche en entresuelo de Casa de la Caridad. }\end{array}$ \\
\hline & Santander & & 1907 & Santander & C.Vieja & $\begin{array}{l}\text { Fernandez Teijeiro (2014)/ } \\
\text { Ulecia (1912) }\end{array}$ & $\begin{array}{l}\text { Presentacion oficial Institución Reina } \\
\text { Victoria Gota de Leche. Dirigida por el doctor } \\
\text { Mariano Morales. }\end{array}$ \\
\hline & Santander & & 1908 & Santander & C.Vieja & $\begin{array}{l}\text { "La Correspondencia de } \\
\text { Valencia" } 3 \text { Agosto } 1908\end{array}$ & $\begin{array}{l}\text { Primera noticia de actividades benéficas de } \\
\text { la asociación "Gota de leche". }\end{array}$ \\
\hline & Santander & & 1916 & Santander & C.Vieja & $\begin{array}{l}\text { "Anuario Estadístico de } \\
\text { España"(1916-1923) }\end{array}$ & $\begin{array}{l}\text { Referencia a litros de leche distribuidos en la } \\
\text { capital en los Anuarios desde } 1916 \text { a } 1923 .\end{array}$ \\
\hline & Santander & 1923 & & Santander & C. Vieja & “La Vanguardia” 9 Marzo 1923 & $\begin{array}{l}\text { Entrega del edificio de la Gota de Leche, } \\
\text { sufragado por santanderinos en Cuba. }\end{array}$ \\
\hline & Santander & & 1929 & Santander & C.Vieja & "ABC" 21 Julio 1929 & $\begin{array}{l}\text { Inaugurada Casa Maternidad de Santander } \\
\text { que incluye Gota de Leche. }\end{array}$ \\
\hline 67 & $\begin{array}{l}\text { Santiago } \\
\text { Compostela }\end{array}$ & & 1912 & La Coruña & Galicia & $\begin{array}{l}\text { "El Noroeste" } 26 \text { Septiembre } \\
1912\end{array}$ & $\begin{array}{l}\text { Propuesta de instalar una Gota de Leche en } \\
\text { la ciudad. }\end{array}$ \\
\hline \multirow[t]{2}{*}{68} & Segovia & 1913 & & Segovia & C.Vieja & $\begin{array}{l}\text { C. Alvaro "La gota de leche" } \\
\text { en "El Norte de Castilla", } 10 \\
\text { Noviembre } 2010 .\end{array}$ & $\begin{array}{l}\text { Fundada por el Dr. Leopoldo Moreno, } \\
\text { instalada en una casa de su propiedad. }\end{array}$ \\
\hline & Segovia & & 1916 & Segovia & C.Vieja & $\begin{array}{l}\text { “Anuario Estadístico } \\
\text { España"(1916-1923) }\end{array}$ & $\begin{array}{l}\text { Referencia a litros de leche distribuidos en la } \\
\text { capital en los Anuarios desde } 1916 \text { a } 1923 .\end{array}$ \\
\hline \multirow[t]{3}{*}{69} & Sevilla & 1906 & & Sevilla & Andalucia & $\begin{array}{l}\text { "Nuevos apuntes......" /Sandino } \\
\text { Agudo (1925) }\end{array}$ & $\begin{array}{l}\text { Iniciativa de doctores con apoyo privado y } \\
\text { público.Dirigida por el Dr. Ciriaco Estebán. }\end{array}$ \\
\hline & Sevilla & & 1916 & Sevilla & Andalucia & $\begin{array}{l}\text { "Anuario Estadístico de España" } \\
(1916-1923)\end{array}$ & $\begin{array}{l}\text { Referencia a litros de leche distribuidos en la } \\
\text { capital en los Anuarios desde } 1916 \text { a } 1923 .\end{array}$ \\
\hline & Sevilla & & 1929 & Sevilla & Andalucia & $\begin{array}{l}\text { "La Vanguardia” } 3 \text { Noviembre } \\
1929\end{array}$ & $\begin{array}{l}\text { Primera piedra del establecimiento benéfico } \\
\text { que pertenece a la Gota de Leche. }\end{array}$ \\
\hline
\end{tabular}




\begin{tabular}{|c|c|c|c|c|c|c|c|}
\hline $\mathbf{n}$ & Localidad & $\begin{array}{c}\text { Año } \\
\text { Inaugura }\end{array}$ & $\begin{array}{l}\text { Año } \\
\text { Actividad }\end{array}$ & Provincia & $\begin{array}{l}\text { Región } \\
\text { Histórica }\end{array}$ & Referencia/Fuente & Observación \\
\hline \multirow[t]{3}{*}{70} & Soria & & 1915 & Soria & C.Vieja & $\begin{array}{l}\text { "El Porvenir Castellano" } 15 \\
\text { Enero } 1915\end{array}$ & $\begin{array}{l}\text { Propuesta de Gota de Leche por el } \\
\text { Gobernador Civil, fracasa por dificultades } \\
\text { económicas. }\end{array}$ \\
\hline & Soria & & 1921 & Soria & C.Vieja & $\begin{array}{l}\text { "Noticiario de Soria" } 2 \\
\text { Diciembre } 1921\end{array}$ & $\begin{array}{l}\text { Reunión de fondos por la Junta de } \\
\text { Proteccion de la Infancia para fundar Gota } \\
\text { de Leche. }\end{array}$ \\
\hline & Soria & & 1930 & Soria & C.Vieja & $\begin{array}{l}\text { "Noticiero de Soria" } 17 \text { Julio } \\
1930\end{array}$ & $\begin{array}{l}\text { Propuesta de presupuesto para instalar Gota } \\
\text { de Leche. }\end{array}$ \\
\hline 71 & $\begin{array}{l}\text { Talavera } \\
\text { de la } \\
\text { Reina }\end{array}$ & 1906 & & Toledo & C.Nueva & $\begin{array}{l}\text { "Nuevos apuntes......" / "El Bien } \\
\text { Público" } 16 \text { Junio } 1906\end{array}$ & Inaugura el Alcalde (Médico). \\
\hline 72 & Tanger & 1921 & & & Norte Africa & $\begin{array}{l}\text { "La Correspondencia" } 8 \text { Enero } \\
\text { 1921/ Martinez Antonio ( } 2013 \text { ) }\end{array}$ & $\begin{array}{l}\text { Inauguración con presencia de un ministro } \\
\text { de España y autoridades locales. }\end{array}$ \\
\hline \multirow[t]{3}{*}{73} & Tarragona & & 1911 & Tarragona & Cataluña & “La Vanguardia” 25 Marzo 1911 & $\begin{array}{l}\text { Acuerdo creación de la Gota de Leche por } \\
\text { Junta Provincial de Protección a la Infancia. }\end{array}$ \\
\hline & Tarragona & 1918 & & Tarragona & Cataluña & “La Cruz" 20 Junio 1918 & $\begin{array}{l}\text { Noticia del funcionamiento de la Gota de } \\
\text { Leche inaugurada ese año. }\end{array}$ \\
\hline & Tarragona & & 1922 & Tarragona & Cataluña & $\begin{array}{l}\text { "Anuario Estadístico de España" } \\
(1916-1923)\end{array}$ & $\begin{array}{l}\text { Referencia a litros de leche distribuidos en la } \\
\text { capital en los Anuarios años } 1922 \text { y } 1923 .\end{array}$ \\
\hline \multirow[t]{2}{*}{74} & Teruel & & 1923 & Teruel & Aragón & "La Provincia" 3 Enero 1923 & $\begin{array}{l}\text { Mencion a una discusion sobre creación de } \\
\text { una Gota de Leche en la capital. }\end{array}$ \\
\hline & Teruel & & 1926 & Teruel & Aragón & $\begin{array}{l}\text { "Diario de Teruel" } 12 \text { Agosto } \\
1926\end{array}$ & $\begin{array}{l}\text { Disponible un local prestado por el } \\
\text { Arzobispado y de presupuesto por el } \\
\text { Ayuntamiento y la Diputación. }\end{array}$ \\
\hline 75 & Terrassa & & 1927 & Barcelona & Cataluña & “La Vanguardia" 7 Octubre 1927 & $\begin{array}{l}\text { Acuerdo de cesion de un edificio para } \\
\text { instalar la Gota Leche. }\end{array}$ \\
\hline \multirow[t]{4}{*}{76} & Toledo & & 1907 & Toledo & C.Nueva & $\begin{array}{l}\text { "La Campana Gorda" } 7 \text { Enero } \\
1907\end{array}$ & Acciones benéficas pro Gota de Leche. \\
\hline & Toledo & 1915 & & Toledo & C.Nueva & $\begin{array}{l}\text { “Diario Toledano" y el “Eco } \\
\text { Toledano" año } 1915\end{array}$ & $\begin{array}{l}\text { Probable año inauguracion dadas las noticias } \\
\text { de actividad y de dirección médica en esa } \\
\text { fecha.. }\end{array}$ \\
\hline & Toledo & & 1916 & Toledo & C.Nueva & $\begin{array}{l}\text { "Anuario Estadístico de España" } \\
(1916-1923)\end{array}$ & $\begin{array}{l}\text { Referencia a litros de leche distribuidos en la } \\
\text { capital en los Anuarios desde } 1916 \text { a } 1923 .\end{array}$ \\
\hline & Toledo & 1928 & & Toledo & C.Nueva & “La Libertad" 10 Enero 1928 & $\begin{array}{l}\text { Inauguracion Gota Leche Institucion fundada } \\
\text { y sostenida pot la Junta Proteccion Infancia } \\
\text { y Cruz Roja. }\end{array}$ \\
\hline 77 & Toro & & 1928 & Zamora & León & "La Vanguardia" 4 Octubre 1928 & $\begin{array}{l}\text { Actividad benéfica para sostenimiento de la } \\
\text { Gota de Leche. }\end{array}$ \\
\hline 78 & Tortosa & 1930 & & Tarragona & Cataluña & "La Vanguardia" 18 Junio 1930 & En un local de la Cruz Roja. \\
\hline 79 & Unión & & 1910 & Murcia & Murcia & $\begin{array}{l}\text { "Boletín Provincial Provincia de } \\
\text { Murcia" } 19 \text { Enero } 1910\end{array}$ & $\begin{array}{l}\text { Estudio de una propuesta para establecer } \\
\text { Gota de Leche .Sin confirmación posterior } \\
\text { de actividad. }\end{array}$ \\
\hline 80 & Utrera & 1910 & & Sevilla & Andalucia & "Nuevos apuntes......" & \\
\hline \multirow[t]{2}{*}{81} & Valencia & 1910 & & Valencia & Valencia & $\begin{array}{l}\text { "Nuevos apuntes......" /"El } \\
\text { Salmantino" } 12 \text { Diciembre } 1910\end{array}$ & $\begin{array}{l}\text { Existe un Consultorio de Niños de Pecho en } \\
\text { Valencia en } 1904 \text { (Maján, 1990). }\end{array}$ \\
\hline & Valencia & & 1916 & Valencia & Valencia & $\begin{array}{l}\text { "Anuario Estadístico de España" } \\
(1916-1923)\end{array}$ & $\begin{array}{l}\text { Referencia a litros de leche distribuidos en la } \\
\text { capital en los Anuarios desde } 1916 \text { a } 1923 .\end{array}$ \\
\hline \multirow[t]{3}{*}{82} & Valladolid & 1910 & & Valladolid & C.Vieja & $\begin{array}{l}\text { "La Vanguardia" } 3 \text { Diciembre } \\
\text { 1910/ Vega Git et alt. (1998) }\end{array}$ & $\begin{array}{l}\text { Inaugurada a fines de } 1910 . \text { Inicia actividad } \\
\text { el } 1 \text { Enero } 1911 \text {. Vega Gil et alt (1998) fechan } \\
\text { en el } 1906 .\end{array}$ \\
\hline & Valladolid & & 1916 & Valladolid & C.Vieja & $\begin{array}{l}\text { “Anuario Estadístico de España" } \\
\text { (1916-1923) }\end{array}$ & $\begin{array}{l}\text { Referencia a litros de leche distribuidos en la } \\
\text { capital en los Anuarios desde } 1916 \text { a } 1923 .\end{array}$ \\
\hline & Valladolid & & 1924 & Valladolid & C.Vieja & $\begin{array}{l}\text { "La Vanguardia" } 9 \text { Septiembre } \\
1924\end{array}$ & $\begin{array}{l}\text { Proyecto de construir Gota de Leche en la } \\
\text { barriada de Los Mostenses. }\end{array}$ \\
\hline 83 & Vigo & 1915 & 1915 & Pontevedra & Galicia & "La Vanguardia" 30 Agosto 1915 & $\begin{array}{l}\text { Dirige doctor Alvárez. Atención sanitaria a } \\
\text { cargo de las Hermanas de la Caridad. }\end{array}$ \\
\hline 84 & Vitoria & 1906 & & Alava & P.Vasco & $\begin{array}{l}\text { "El Heraldo Alavés" } 17 \text { Abril } \\
1906\end{array}$ & $\begin{array}{l}\text { Después de discusiones sobre ubicación se } \\
\text { instala en el Hospicio. }\end{array}$ \\
\hline
\end{tabular}




\begin{tabular}{|c|c|c|c|c|c|c|c|}
\hline $\mathrm{n}$ & Localidad & $\begin{array}{c}\text { Año } \\
\text { Inaugura }\end{array}$ & $\begin{array}{l}\text { Año } \\
\text { Actividad }\end{array}$ & Provincia & $\begin{array}{l}\text { Región } \\
\text { Histórica }\end{array}$ & Referencia/Fuente & Observación \\
\hline & Vitoria & & 1916 & Alava & P.Vasco & $\begin{array}{l}\text { "Anuario Estadístico de España" } \\
(1916-1923)\end{array}$ & $\begin{array}{l}\text { Referencia a litros de leche distribuidos en la } \\
\text { capital en los Anuarios desde } 1916 \text { a } 1923 .\end{array}$ \\
\hline & Vitoria & 1927 & & Alava & P.Vasco & $\begin{array}{l}\text { "La Vanguardia" } 25 \text { Diciembre } \\
1927\end{array}$ & $\begin{array}{l}\text { Inauguración de nuevos locales de la Gota } \\
\text { de Leche. }\end{array}$ \\
\hline \multirow[t]{4}{*}{85} & Zamora & & 1906 & Zamora & León & "ABC" 26 Mayo 1906 & $\begin{array}{l}\text { Propuesta del Gobernador Civil de instituir } \\
\text { una Gota de Leche. }\end{array}$ \\
\hline & Zamora & 1916 & & Zamora & León & $\begin{array}{l}\text { “Heraldo de Zamora” } 26 \text { Junio } \\
1916\end{array}$ & $\begin{array}{l}\text { Instalada en un local del Colegio del Amor } \\
\text { de Dios. }\end{array}$ \\
\hline & Zamora & & 1916 & Zamora & León & $\begin{array}{l}\text { "Anuario Estadístico de España" } \\
(1916-1923)\end{array}$ & $\begin{array}{l}\text { Referencia a litros de leche distribuidos en la } \\
\text { capital en los Anuarios desde } 1916 \text { a } 1923 .\end{array}$ \\
\hline & Zamora & & 1931 & Zamora & León & $\begin{array}{l}\text { "Heraldo de Zamora" } 7 \text { Octubre } \\
1931\end{array}$ & $\begin{array}{l}\text { Traslado Gota de Leche a nuevo local cedido } \\
\text { por la Diputación. }\end{array}$ \\
\hline \multirow[t]{3}{*}{86} & Zaragoza & 1905 & & Zaragoza & Aragón & Ulecia (1912) & $\begin{array}{l}\text { Fundación Gota de Leche por farmaceúticos } \\
\text { Tomas Bayod y Miguel Bel }\end{array}$ \\
\hline & Zaragoza & 1907 & & Zaragoza & Aragón & "Nuevos apuntes......" & \\
\hline & Zaragoza & & 1916 & Zaragoza & Aragón & $\begin{array}{l}\text { "Anuario Estadístico de España" } \\
(1916-1923)\end{array}$ & $\begin{array}{l}\text { Referencia a litros de leche distribuidos en la } \\
\text { capital en los Anuarios desde } 1916 \text { a } 1923 .\end{array}$ \\
\hline
\end{tabular}

